\title{
Studies on the Role of the Transcription Factor Tcf21 in the Transdifferentiation of Parietal Epithelial Cells into Podocyte-Like Cells
}

\author{
Felix Kliewe $^{\mathrm{a}}$ Andreas W. Kuss ${ }^{\mathrm{b}} \quad$ Florian Siegerist $^{\mathrm{a}} \quad$ Sindy Schröder ${ }^{\mathrm{a}}$ \\ Sandra Schordan ${ }^{\mathrm{a}}$ Nadine Artelt ${ }^{\mathrm{a}} \quad$ Frances Kindt $^{\mathrm{a}}$ Kerstin Amann ${ }^{\mathrm{c}}$ \\ Maja T. Lindenmeyer ${ }^{d} \quad$ Karlhans Endlich ${ }^{a} \quad$ Nicole Endlich $^{a}$
}

\begin{abstract}
aDepartment of Anatomy and Cell Biology, University Medicine Greifswald, Greifswald, Germany, bHuman Molecular Genetics Group, Department of Functional Genomics, University Medicine Greifswald, Greifswald, Germany, 'Department of Nephropathology, University Medicine Erlangen, Erlangen, Germany, 'Department of Medicine, University Medical Center Hamburg-Eppendorf, Hamburg, Germany
\end{abstract}

\section{Key Words}

Tcf21 • Parietal epithelial cells $\bullet$ ChIP-Seq $•$ Differentiation $\bullet$ Podocyte $\cdot$ Transcription factors

\begin{abstract}
Background/Aims: Podocyte differentiation is essential for proper blood filtration in the kidney. It is well known that transcription factors play an essential role to maintain the differentiation of podocytes. The present study is focused on the basic helix-loop-helix (bHLH) transcription factor Tcf21 (Pod1) which is essential for the development of podocytes in vivo. Since parietal epithelial cells (PECs) are still under debate to be progenitor cells which can differentiate into podocytes, we wanted to find out whether the expression of Tcf21 induces a transition of PECs into podocytes. Methods: We transfected PECs with Tcf21-GFP and analyzed the expression of PEC- and podocyte-specific markers. Furthermore, we performed ChIP-Seq analysis to identify new putative interaction partners and target genes of Tcf21. Results: By gene arrays analysis, we found that podocytes express high levels of Tcf21 in vivo in contrast to cultured podocytes and parietal epithelial cells (PECs) in vitro. After the expression of Tcf2 1 in PECs, we observed a downregulation of specific PEC markers like caveolin-1, $\beta$-catenin and Pax2. Additionally, we found that the upregulation of Tcf21 induced multi-lobulation of cell nuclei, budding and a formation of micronuclei (MBM). Furthermore, a high number of PECs showed a tetraploid set of chromosomes. By qRT-PCR and Western blot analysis, we revealed that the transcription factor YY1 is downregulated by Tcf21. Interestingly, co-expression of YY1 and Tcf21 rescues MBM and reduced tetraploidy. By ChIP-Seq analysis, we identified a genome-wide Tcf21-
\end{abstract}




\section{Cellular Physiology Cell Physiol Biochem 2021;55:48-67

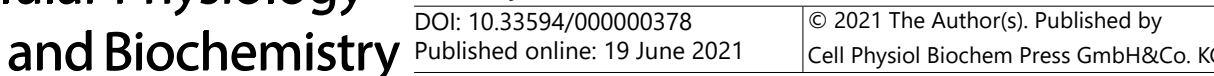 \\ Kliewe et al.: The Role of Tcf21 for Transdifferentiation of PECs to Podocytes}

binding site (CAGCTG), which matched the CANNTG sequence, a common E-box binding motif used by bHLH transcription factors. Using this technique, we identified additional Tcf21 targets genes that are involved in the regulation of the cell cycle (e.g. Mdm2, Cdc45, Cyclin D1, Cyclin D2), on the stability of microtubules (e.g. Mapt) as well as chromosome segregation. Conclusion: Taken together, we demonstrate that Tcf 21 inhibits the expression of PEC-specific markers and of the transcription factor YY1, induces MBM as well as regulates the cell cycle suggesting that Tcf21 might be important for PEC differentiation into podocyte-like cells.

(c) 2021 The Author(s). Published by Cell Physiol Biochem Press GmbH\&Co. KG

\section{Introduction}

Over the last years, many studies have demonstrated that the de-differentiation and loss of podocytes are the major cause of chronic kidney disease (CKD) [1-3]. It would be therefore worthwhile to find a strategy to replace lost and damaged podocytes as it is already described for the transdifferentiation of fibroblasts into several different cell types, e.g. neurons. This transdifferentiation was induced by the expression of a small number of specific transcription factors. Whether there are progenitor cells which are able to differentiate into podocytes is still an ongoing and controversial debate. One hypothesis is that parietal epithelial cells (PECs) are able to transdifferentiate into podocytes to some extent and under specific circumstances [4-12]. Since in the literature it is described that several transcription factors are crucial for podocyte differentiation like Wt 1 , Lmx1b, Foxc2, and MafB [13-16], we focused our attention on a transcription factor of the basic-loophelix family, Tcf 21 which was already shown to be essential for the proper development of glomeruli $[17,18]$.

Tcf21, also known as Pod1, capsulin, or epicardin, is not only crucial for the differentiation of immature podocytes but also for a number of different cell types during embryogenesis of the heart, lung, kidney and spleen [17-22]. By the generation of Tcf21 null mutant mice that die at the perinatal period by major cardiopulmonary defects, it was nicely demonstrated that Tcf21 is essential for development [18]. Additionally, it was shown that the kidneys of the Tcf 21 knockout mice were severely hypoplastic due to a delay of nephrogenesis and abnormal branching of the ureteric bud. The few glomeruli found in kidneys of Tcf21 knockout mice appeared to arrest at the capillary loop stage of development [18]. Moreover, podocyte-specific Tcf21 knockout mice developed massive proteinuria at 3-5 weeks of age with prominent glomerular lesions which is similar to human FSGS [23].

Because Tcf21 is so important for proper kidney development and function, we studied the influence of Tcf 21 for the differentiation of PECs into podocytes in vitro and looked for target genes by Chromatin ImmunoPrecipitation followed by DNA-Sequencing (ChIP-Seq).

\section{Materials and Methods}

\section{Cell culture}

PECs were cultivated in EBM medium (Lonza, Basel, Switzerland) supplemented with EGM-MV singlequots T75 (Lonza) as reported [24]. PECs were passaged every 3-4 days. Transfection of PECs was done with $1 \mu \mathrm{g} / \mathrm{ml}$ GFP- and the Tcf21-GFP plasmids (OriGene Technologies, Rockville, MD, USA) by Lipofectamine ${ }^{\circledR} 2000$ transfection (Invitrogen, Carlsbad, CA, USA) in serum-free RPMI medium (Lonza) according to the manufacturer's instructions. Cells were used 48 hours after transfection for immuncytochemistry, for protein- and RNA-isolation.

\section{In Situ Cell Death Detection (TUNEL assay)}

The In Situ Cell Death Detection Kit, TMR red (Sigma-Aldrich, St. Louis, MO, USA) is based on the detection of single- and double-stranded DNA breaks that occur at the early stages of apoptosis. Apoptotic cells were fixed and permeabilized. Subsequently, the cells are incubated with the TUNEL reaction. After washing, the label incorporated at the damaged sites of the DNA is visualized by fluorescence microscopy. 


\section{Cellular Physiology Cell Physiol Biochem 2021;55:48-67 \\ \begin{tabular}{ll|l} 
and Biochemistry $10.33594 / 000000378$ & Dublished online: 19 June 2021 & 2021 The Author(s). Published by \\
Cell Physiol Biochem Press GmbH 8 C
\end{tabular} \\ Kliewe et al.: The Role of Tcf21 for Transdifferentiation of PECs to Podocytes}

\section{BrdU Labeling and Detection}

Cell proliferation was measured with the thymidine analog BrdU (5-bromo-2'-deoxyuridine) following its incorporation into newly synthesized DNA and its subsequent detection with an anti-BrdU antibody by using "5-Bromo-2'-deoxy-uridine Labeling and Detection Kit I" (Roche, Basel, Switzerland)

\section{Histology}

For paraffin sections of mouse kidneys and human biopsies, samples were dehydrated and embedded into paraffin by standard procedures. Paraffin sections $(5 \mu \mathrm{m})$ were done on a Leica SM 2000R (Leica Microsystems, Wetzlar, Germany). After rehydration, sections were unmasked in citrate buffer (0.1 M, pH 6.0) by heating for $5 \mathrm{~min}$ in a pressure cooker. The sections were stained with $1 \mathrm{mg} / 100 \mathrm{ml}$ Hoechst 33342 (SigmaAldrich) for $30 \mathrm{~min}$. For the immunofluorescence double-staining, samples were incubated with an antibody against synaptopodin (1:50; mouse; Progen Biotechnik GmbH, Heidelberg, Germany) and Tcf21 (rabbit; Sigma-Aldrich, HPA013189, 1:100) overnight. Samples were washed with 1x PBS for 3x 5 min and incubated with Cy2- and Cy3-conjugated anti-mouse/-rabbit secondary antibodies (1:250; Jackson ImmunoResearch Laboratories, West Grove, USA) for 1 hour. After additional washing, the samples were mounted in Mowiol (Carl Roth, Karlsruhe, Germany) for fluorescence microscopy. Additionally, paraffin sections were stained using the Vectastain kit (Vector Laboratories, Burlingame, CA, USA) following manufacturer's instructions. Visualization was performed with DAB substrate kit (SK-4100; Vector Laboratories) followed by nuclear staining with hematoxylin and mounting in Eukitt (Sigma-Aldrich). In controls, 1x PBS was used instead of primary antibody. Photographs were taken on an Olympus BX50 microscope equipped with an Olympus DP10 digital camera (Tokyo, Japan).

\section{Kidney biopsies}

Kidney biopsies were archived at the Department of Nephropathology, Institute of Pathology, University Hospital Erlangen, Germany. The use of remnant kidney biopsy material was approved by the Ethics Committee of the Friedrich-Alexander-University of Erlangen-Nürnberg, waiving the need for retrospective consent for the use of archived rest material.

\section{Immunocytochemistry}

PECs were fixed with 2\% paraformaldehyde (PFA) for $10 \mathrm{~min}$, permeabilized by $0.3 \%$ Triton-X (SigmaAldrich) for $4 \mathrm{~min}$ and blocked for 1 hour with blocking solution (2\% FBS, 2\% BSA and 0.2\% fish gelatin in PBS). Primary antibodies were diluted in blocking solution and incubated for 1 hour on cells. Antibodies used in this study for immunocytochemistry can be viewed in Supplementary Table 1 (for all supplementary material see www.cellphysiolbiochem.com). Secondary antibodies were diluted in blocking solution and incubated with the cells for 30 min: anti-mouse-Cy3 (Jackson ImmunoResearch Laboratories, 1:300) and anti-rabbit-Cy3 (Jackson Immuno Research, 1:300). For the visualization of the actin cytoskeleton, cells were stained with Alexa Fluor 546 phalloidin (1:100; Thermo Fisher Scientific, Waltham, MA, USA) for $30 \mathrm{~min}$. For nuclei staining DAPI (1:150; Sigma-Aldrich) was used for $5 \mathrm{~min}$. All samples were mounted in Mowiol (Carl Roth, Karlsruhe, Germany) and used for laser scanning microscopy (LSM).

Fluorescence mRNA in situ hybridization (FISH). For mRNA FISH, we used the RNAscope 2.5 HD Assay Red (Advanced Cell Diagnostics, Newark, CA, USA). Protocol was applied according to manufacturer's instructions with following changes: Tissue was digested for 15 instead of 30 min to yield better glomerular morphology. After FastRed detection, slides were collected in 1x PBS, blocked with the aforementioned blocking solution for 1 hour at room temperature. A premixed antibody solution containing a rabbit antihuman podocin antibody (1:150, IBL, Cat No. 29040) and an Alexa Fluor 488-conjugated dual monoclonal alpaka anti-rabbit VHH nanobody (1:1000, ChromoTek GmbH, Planegg-Martinsried, Germany) was incubated at $4^{\circ} \mathrm{C}$ overnight. After several washes in PBS, cell nuclei were counterstained with $0.1 \mathrm{mg} / \mathrm{ml}$ DAPI and sections mounted in Mowiol for microscopy.

Microarrays on human kidney biopsies. Human renal biopsy specimens and Affymetrix microarray expression data were procured within the framework of the European Renal cDNA Bank - Kröner-Fresenius Biopsy Bank [25, 26]. Biopsies were obtained from patients after informed consent and with approval of the local ethics committees. Following renal biopsy, the tissue was transferred to RNase inhibitor and microdissected into glomeruli and tubulointerstitium. Total RNA was isolated from microdissected glomeruli, reverse transcribed, and linearly amplified according to a protocol previously reported [27]. 


\section{Cellular Physiology Cell Physiol Biochem 2021;55:48-67

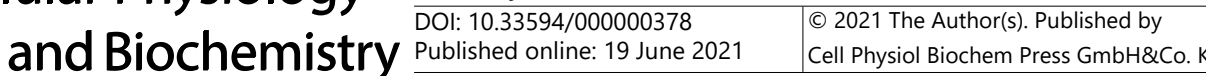 \\ Kliewe et al.: The Role of Tcf21 for Transdifferentiation of PECs to Podocytes}

The published microarray expression data used in this study came from individual patients with DN and FSGS. Pre-transplantation kidney biopsies from living donors were used as control renal tissue (GSE99340, GSE32591, GSE37463). Fragmentation, hybridization, staining, and imaging were performed with the Affymetrix HG-U 133plus 2.0 system (Affymetrix, Santa Clara, CA) according to the Affymetrix Expression Analysis Technical Manual. CEL file normalization was performed with the Robust Multichip Average method using RMAExpress (Version 1.0.5) and the human Entrez-Gene custom CDF annotation from Brain Array version 18. The log-transformed dataset was corrected for batch effect using ComBat from the GenePattern pipeline (http://www.broadinstitute.org/cancer/software/genepattern/). To identify differentially expressed genes the SAM (Significance Analysis of Microarrays) method was applied using TiGR (MeV, Version 4.8.1) [28]. A q-value below 0.05 was considered to be statistically significant.

\section{Laser scanning microscopy}

Images were captured either with a Leica TCS SP5 confocal microscope (Leica Microsystems, Wetzlar, Germany), 40x/63x oil immersion objectives in the Leica Application Suite software (Leica Microsystems, Version 2.6.0).

\section{RNA extraction, $c D N A$ synthesis, $q R T-P C R$}

Samples from cells/tissues were processed in Tri-Reagent (Sigma-Aldrich, St. Louis, MO, USA) according manufactures instructions. For cDNA synthesis, $1 \mu \mathrm{g}$ of the isolated total RNA was transcribed using the QuantiTect Reverse Transcription Kit (Qiagen, Hilden, Germany). The quantitative real-time PCR (qRT-PCR) analysis was performed on a LightCycler Nano (Roche Diagnostics GmbH, Mannheim, Germany) by using the iTaq Universal SYBR Green Supermix (Bio-Rad, Hercules, CA, USA) with Actb and Rpl32 as reference genes. Relative quantifications of the mRNA levels were done by the efficiency corrected calculation model by Pfaffl [29] and are shown with standard deviations from three biological replicates. Primers used for mouse samples can be viewed in Supplementary Table 2.

Expression level of mRNA corresponding to Tcf21 (ENSMUSG00000045680) was also determined by RNA sequencing of samples isolated from murine glomeruli. Sequencing was carried out on a SOLiD 5500xl sequencing platform (Life Technologies, Carlsbad CA, USA) as previously described [30]. Sequence analysis was based on GRCm38/mm10. Benjamini-Hochberg adjusted Wald test p-values ( $\mathrm{p}_{\text {adj }}$ ) were determined to identify significant differences in gene expression between samples.

\section{Western blot analysis}

Cells were trypsinized, washed twice in PBS and dissolved in RIPA lysis buffer (Thermo Fisher Scientific). Protein homogenates were quantified using the Pierce BCA protein assay kit (Thermo Fisher Scientific). After addition of SDS-PAGE sample buffer (final concentrations: $32 \mathrm{mM}$ Tris-HCl, 1\% SDS, 5\% glycerol, $0.05 \%$ bromphenol blue, 3.25\% 2-mercaptoethanol, $\mathrm{pH} 6.8$ ), the cell lysates were heated at $95^{\circ} \mathrm{C}$, 5 min and separated on a 4-20\% gradient Mini-Protean TGX Gel (Bio-Rad). Furthermore, separated proteins were blotted on nitrocellulose membranes using the Trans-Blot Turbo RTA Transfer Kit (Bio-Rad) and the Trans-Blot Turbo Transfer System (Bio-Rad) at 1.3 A/25 V for $10 \mathrm{~min}$. Blots were washed in 1x TBST (50 mM Tris, $150 \mathrm{mM} \mathrm{NaCl}, 10 \mathrm{mM} \mathrm{CaCl}_{2}, 1 \mathrm{mM} \mathrm{MgCl}$ ) supplemented with Tween-20 0.1\%; AppliChem) and blocked with 5\% milk powder for 1 hour at room temperature. Moreover, primary antibodies were diluted in $2.5 \%$ milk powder (in 1x TBST) and incubated over night by $4^{\circ} \mathrm{C}$. After intensive washing in $1 \mathrm{x}$ TBST blots were incubated with secondary antibodies for $60 \mathrm{~min}$, washed again, developed with the Clarity ${ }^{\mathrm{TM}}$ Western ECL Substrate (Bio-Rad) and visualized on X-ray films (Fujifilm Super RX, FUJIFILM, Tokyo, Japan). Antibodies used in this study for Western blot can be viewed in Supplementary Table 3. For the relative quantification, developed x-ray films were scanned and analyzed using Image (version 1.49m; NIH, Bethesda, MD, USA).

\section{ChIP-Seq and bioinformatic analysis}

PECs were transfected with Tcf21-myc and myc empty vector (control plasmid) for $48 \mathrm{~h}$. Cells were treated with $1 \%$ formaldehyde for $10 \mathrm{~min}$ at room temperature. Formaldehyde was inactivated by adding glycine (final concentration $0.125 \mathrm{M}$ ) to the cells, followed by two times washing with cold PBS. Cells were lysed for $10 \mathrm{~min}$ on ice (20mM HEPES pH 7.4,1mM EDTA, 150mM NaCl, 1\% SDS, protease inhibitor). Nuclei were collected by centrifugation ( $1700 \mathrm{~g}$ for $5 \mathrm{~min})$ and resuspended for sonication in shearing buffer $(20 \mathrm{mM}$ HEPES pH 7.4, 1mM EDTA, 150mM NaCl, 0.4\% SDS, protease inhibitor). Crosslinked chromatin was sheared 


\section{Cellular Physiology Cell Physiol Biochem 2021;55:48-67

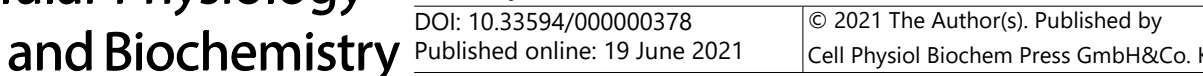 \\ Kliewe et al.: The Role of Tcf21 for Transdifferentiation of PECs to Podocytes}

for $10 \mathrm{~min}$ (duty cycle $5 \%$ by sonication using a Covaris S220 Focused-ultrasonicator (Covaris, Woburn, MA 01801, USA) and pre-cleared with protein A/G agarose (Santa Cruz Biotechnology). ChIP was performed overnight in IP dilution buffer (20 mM Tris pH 8.1, 2 mM EDTA, $150 \mathrm{mM} \mathrm{NaCl}, 1 \%$ Triton X100, 0.01\% SDS), using $5 \mu$ g anti-TCF21 (H-75; sc-32914; Santa Cruz), anti-myc antibody (9E10; sc-40; Santa Cruz), control IgG or anti-myc (9E10) magnetic beads (OriGene Technologies, Rockville, MD, USA). IP complexes were washed twice with wash buffer 1 (100 mM Tris pH 8.0, $500 \mathrm{mM} \mathrm{LiCl,1 \%} \mathrm{NP-40} \mathrm{and} \mathrm{1 \%} \mathrm{deoxycholate),} \mathrm{two} \mathrm{times}$ with high salt wash buffer (1X PBS, $1 \%$ NP-40, 0.5\% sodium deoxycholate, $0.1 \%$ SDS) and twice with TE buffer. Bound chromatin was eluted from the protein $\mathrm{A} / \mathrm{G}$ agarose or beads respectively twice with elution buffer (1\% SDS, $0.1 \mathrm{M} \mathrm{NaHCO}_{3}$ ). After reverse-crosslinking, RNaseA and proteinase $\mathrm{K}$ digestion, chromatin was cleaned up and the DNA concentration measured using Qubit 2.0 fluorometric quantitation. The DNA fragments were then prepared for sequencing on a 5500xl SOLiD system (Life Technologies, Carlsbad, CA, USA) using recommended protocols and equipment (Life Technologies, Carlsbad, CA, USA). In short: The DNA fragments were end-polished, size-selected using Ampure XP Beads (Beckman Coulter, Brea, Ca, USA) and subject to A-tailing, adapter ligation and barcoding. The library was purified and the concentration and size distribution was determined using a 2100 Bioanalyzer Instrument (Agilent Technologies, Santa Clara, CA, USA). The DNA library was then diluted and attached to beads during clonal emulsion PCR amplification using an Applied Biosystems SOLiD EZ Bead Amplifier (Life Technologies, Carlsbad, CA, USA). After enrichment and 3' modification the library was immobilized onto a flowchip and sequenced (75 bases in the forward and 35 bases in the reverse direction) using a 5500xl SOLiD system (Life Technologies, Carlsbad, CA, USA). The Lifescope Genomic Analysis Software (Life Technologies, Carlsbad, CA, USA) was used to call the bases and generate BAM files by alignment of the reads to the mouse genome (GRCm38/ mm10). To identify putative Tcf21-myc binding sites the BAM data files were analysed using MACS1.4 or the GENOMATIX software suite.

De novo motif discovery was performed by using MEMESuite [31], more precisely DREME (Discriminative Regular Expression Motif Elicitation) motif comparison [32] was performed against a database of pooled TF motifs (JASPAR database) [33]. Functional annotation of high confidence binding regions was performed using Database for Annotation, Visualization and Integrated Discovery (DAVID) [34]. Gene enrichment analysis was performed by ToppGene Suite [35]. For visual inspection of Tcf21 binding to specific genomic regions, normalized read densities were uploaded to the Integrative Genomics Viewer (IGV) [36]. Identical viewing range for both Tcf21 and control samples set to the maximum peak within the window. To create density distributions (heat maps) around TSSs of Tcf21 peaks/targets, Seqminer v.1.3.3 was used [37].

\section{Statistical analysis}

All data are given as means \pm SD or \pm SEM, analyzed by unpaired $t$ test with repeated measurements $(n)$. Differences were determined significant at a $p$-value $<0.05$.

\section{Results}

Tcf21 is down-regulated during the de-differentiation of podocytes

As shown in Fig. 1A, Tcf21 is strongly expressed in kidney sections. Co-localization studies using the podocyte-specific protein synaptopodin confirmed that Tcf21 is strongly expressed in the nuclei of mouse and human podocytes (Fig. 1A). In contrast, parietal epithelial cells (PECs) which are still under debate regarding their role as progenitor cells for podocytes, weakly expressed Tcf 21 in vivo (Fig. 1A). This was confirmed by single mRNA in situ hybridization (RNAscope ${ }^{\circledR}$ ) combined with podocin immunofluorescence of human kidneys (Fig. 1B).

To study the expression of Tcf 21 in dependence on the differentiation of podocytes, we performed comparative gene expression analysis of freshly isolated mouse podocytes, cultured primary mouse podocytes as well as cultured primary mouse PECs. We have found that Tcf 21 was one of the strongest expressed genes in freshly isolated podocytes (27-fold) compared to podocytes and PECs in vitro (Fig. 1C). Furthermore, to study the expression of Tcf21 during the de-differentiation of podocytes, we used our established GlomAssay [38]. 


\section{Cellular Physiology and Biochemistry

Fig. 1. Tcf21 expression in mouse kidney and cell culture. (A) Expression of Tcf21 and synaptopodin in mouse glomeruli imaged by LSM $(n=3)$. Mouse kidney paraffin sections were stained with Hoechst (DNA, blue) and with antibodies against synaptopodin (green) and Tcf21 (magenta). Scale bar represents $10 \mu \mathrm{m}$. (B) In situ hybridization of human kidney with a specific TCF21 probe. Podocytes (marked by arrows) showed a strong expression of TCF21. PECs (marked by circles) showed only a slight expression. Nuclei were stained with Hoechst (blue). Immunostaining of podocin is shown in green. Scale bars represent $25 \mu \mathrm{m}$ and $10 \mu \mathrm{m}$ respectively. (C) Tcf21 mRNA fold enrichment from gene expression analysis from freshly isolated (in vivo) glomeruli compared to cultured (in vitro) primary podocytes and cultured primary PECs. (D) Isolated glomeruli express CFP in podocytes under control of the nephrin promoter.

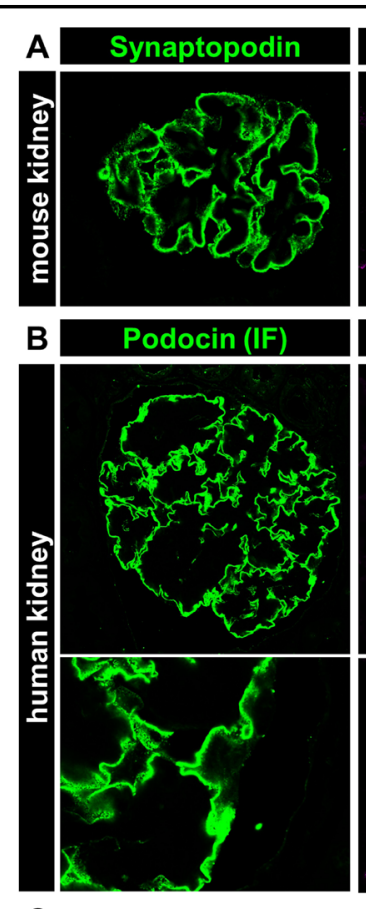

C

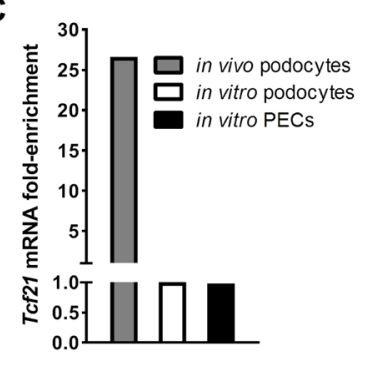

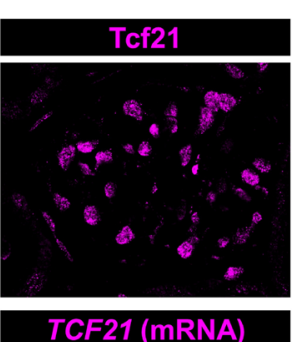
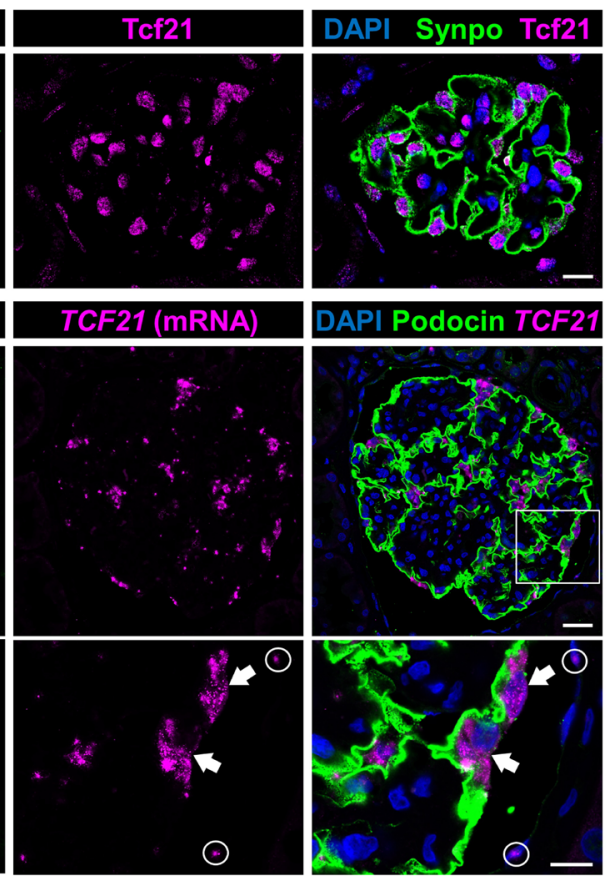

D

E
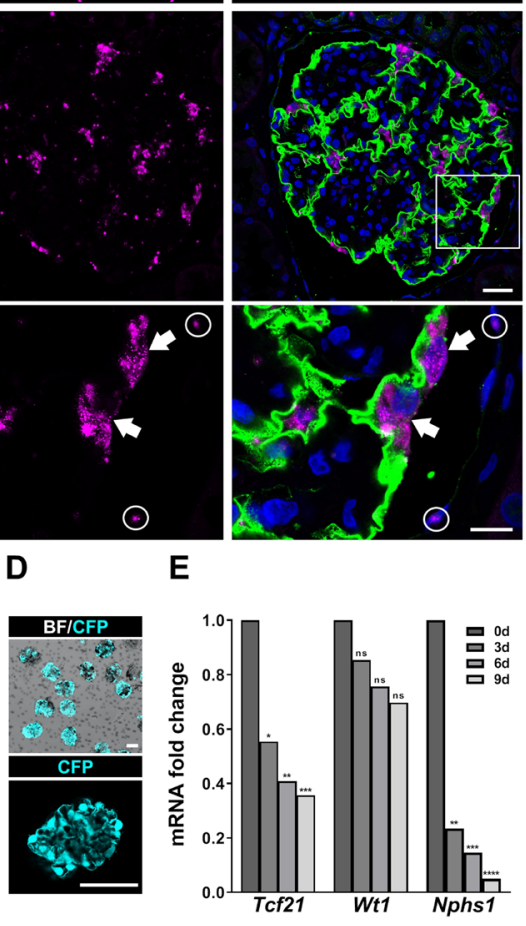

BF - bright field. Scale bars rep-

resent $50 \mu \mathrm{m}$. (E) Tcf21, Wt1 and Nphs1 mRNA level of isolated glomeruli until 9 days of cultivation and transdifferentiation. The mRNA fold enrichment was normalized to day 0 and showed a significant decrease of Tcf21 expression. Benjamini-Hochberg adjusted Wald test $\mathrm{p}$-values $\left(\mathrm{p}_{\text {adj }}\right.$ ) were determined to identify significant differences in gene expression between samples. ${ }^{* * *} \mathrm{p}<0.001,{ }^{* *} \mathrm{p}<0.01,{ }^{*} \mathrm{p}<0.05$.

This assay allows us to study podocytes directly in situ. After isolation, glomeruli were cultured under standard conditions and RNA was isolated after 3, 6 and 9 days followed by RNA_Seq analysis [38]. We have found a continuous decrease of Tcf21 mRNA until day 9 (fold change 3d: 0.55; $p_{\text {adj }}=0.025 ; 6 \mathrm{~d}: 0.41 ; \mathrm{p}_{\text {adj }}=0.0045 ; 9 \mathrm{~d}: 0.36 ; \mathrm{p}_{\text {adj }}=0.0004$ ) (Fig. 1D) indicating a strong downregulation during the de-differentiation of podocytes.

\section{Tcf21 regulates the expression of specific PEC and podocyte markers}

Since it is still under debate that PECs might be a type of progenitor cells that could differentiate into podocytes, we studied the effect of Tcf21 on PECs. Therefore, we transfected PECs with a plasmid encoding for Tcf21 coupled to GFP (PEC-Tcf21). As a control, PECs were transfected with a plasmid encoding for GFP alone (PEC-Ctrl). The expression levels of transfected Tcf21 were quantified by Western blots (Fig. 2C and Supplementary Fig. 1). Using an antibody specific for Tcf21, we verified that PEC-Tcf21 expresses Tcf21GFP (Fig. 2A). We found that Tcf21-GFP was exclusively localized in the nuclei of PEC-Tcf21 (Fig. 2A). Further, we observed no significant change of the cell morphology and the actin cytoskeleton, respectively, as shown in Fig. 2B. 

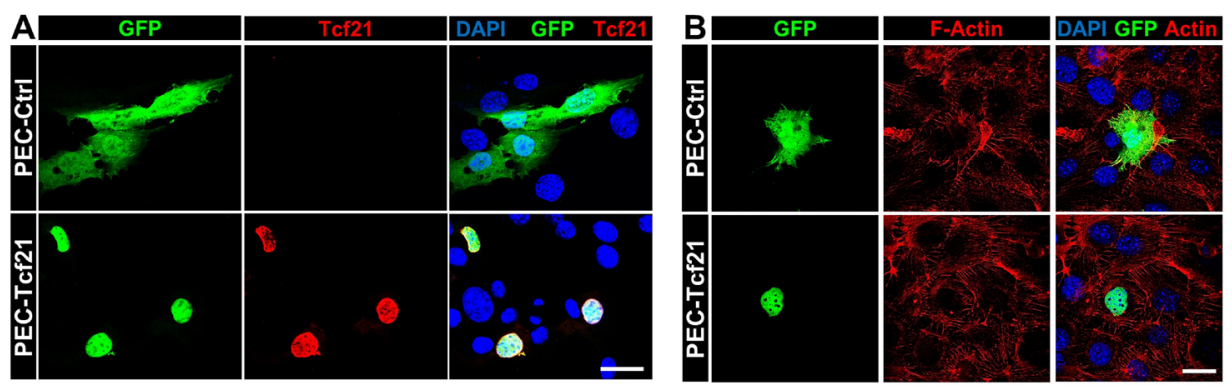

C

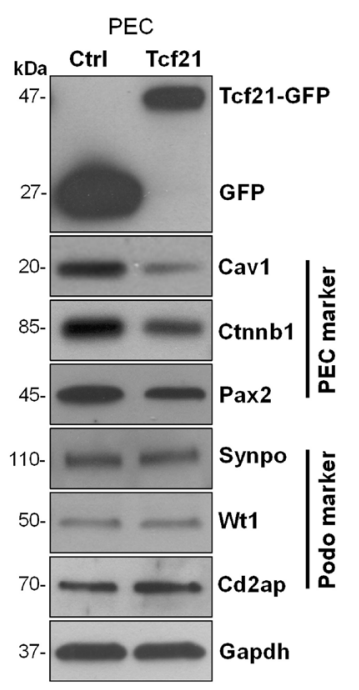

D $\bar{d}$

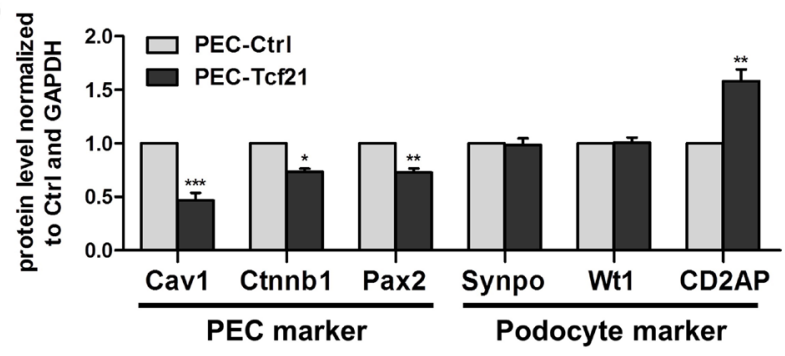

$E$

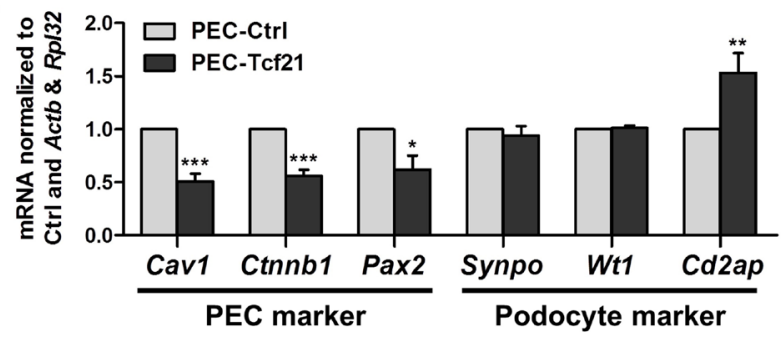

$\mathbf{F}$
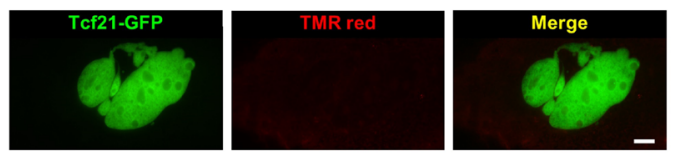

G
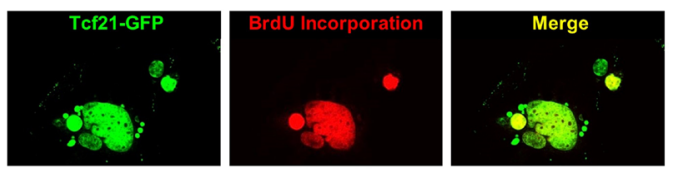

H
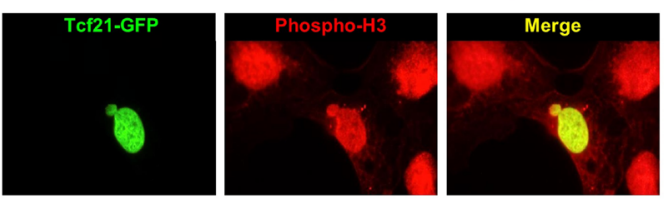

Fig. 2. Effect of Tcf21 expression in PECs on PEC and podocyte markers. (A) Transfection of PECs with pTcf21-GFP causes a strong Tcf21 expression compared to cells transfected with pGFP (PEC-Ctrl) shown by immunofluorescence. (B) Phalloidin staining was done to analyze possible effects on the actin cytoskeleton, whereby no effects could be observed. (C) Western blot analysis of PEC- and podocyte marker. Used protein

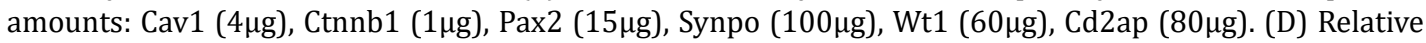
protein levels on Western blots were quantified for PEC-Ctrl (light grey bars) and PEC-Tcf21 (dark grey bars) ( $\mathrm{n} \geq 3$, means \pm SEM). Western blots were normalized to PEC-Ctrl and Gapdh levels. (E) PEC marker genes (Cav1, Ctnnb1 and Pax2) and podocyte marker genes (Synpo, Wt1 and Cd2ap), were quantified by qRTPCR analysis of total mRNA isolated from PEC-Ctrl and PEC-Tcf21. qRT-PCR experiments were normalized to PEC-Ctrl. Actb and Rpl32 served as reference genes ( $\mathrm{n} \geq 3$, means $\pm \mathrm{SEM}){ }^{* * *} \mathrm{p}<0.001,{ }^{* *} \mathrm{p}<0.01,{ }^{*} \mathrm{p}<0.05$. (F) Transfection of PECs with Tcf21-GFP induces MBM, what is not the result of apoptosis, shown by TUNEL assay (using TMR red). (G) Tcf21-transfected cells showed intact BrdU (thymidine analog) incorporation into cellular DNA during cell proliferation. Visualization by using anti-BrdU antibody (shown in red). (H) Immunostaining of phosphorylated histone $\mathrm{H} 3$ (red) detects intact mitosis in Tcf21 transfected cells. Scale bars represent $25 \mu \mathrm{m}$. Colors are green for GFP and Tcf21-GFP (A, B, F-H), red for Tcf21 (A) or F-actin (B) and blue for DAPI-stained DNA (A, B). 
To find out whether PEC-Tcf21 differentiate into podocyte-like cells, we determined the expression of specific PEC as well as podocytes markers by qRT-PCR and Western blot. Western blot analysis showed that specific PEC markers became regulated by Tcf21:

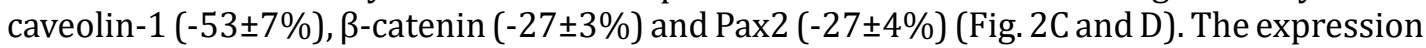
of the podocyte-specific markers synaptopodin (Synpo) and Wt1 did not change due to the transfection of Tcf21, in contrast to the slit membrane protein Cd2ap that was significantly upregulated $(58 \pm 11 \%)$ in PEC-Tcf21 compared to the control. Similar results were received by qRT-PCR (Cav1: $-49 \pm 7 \%$; Ctnnb1: $-44 \pm 6 \%$; Pax2: $-38 \pm 13 \%$, Cd2ap: 55 $\pm 17 \%$ ) (Fig. 2E). Furthermore, the RNA expression of synaptopodin as well as Wt1 was not affected by Tcf21 transfection.

\section{Tcf21 induces multilobulation, budding and micronuclei formation (MBM) in PECs}

Interestingly, we observed that the expression of Tcf21 in PECs affected the nuclei of PEC-Tcf21. Three typical characteristics, like multilobulation, budding of nuclei as well as the formation of micronuclei (MBM) were found 48 hours after transfection. To identify whether these changes are caused by an induction of apoptosis in PECs, we performed a TUNEL assay that detects single- and double-stranded DNA breaks as a sign of apoptosis. However, we have not found any indication for apoptosis (Fig. 2F). Surprisingly, we observed DNA synthesis (Fig. 2G and H) verified by BrdU incorporation (Fig. 2G) as well as by the detection of phosphorylated histone H3 (Fig. 2H). These results suggest that Tcf21 induces mitosis in PEC cells.

\section{Tcf21 induced MBM is accompanied by multiple incomplete mitoses}

Since we observed DNA synthesis together with MBM in PEC-Tcf21, we studied mitosis by staining for $\alpha$-tubulin as one monomer of microtubules and $\gamma$-tubulin, the major tubulin of centrosomes. In contrast to the control-transfected PEC, we found that MBM (Fig. 3A) was accompanied by a multiplication of centrosomes (Fig. 3B). Furthermore, we have found that this multilobulation was reversible after the addition of the microtubule inhibitors nocodazole as well as taxol (Fig. 3C). Incubation with cytochalasin D, an inhibitor of the polymerization of actin, did not affect the number of cells with multilobulated nuclei (Fig. 3C).

Additionally, we have found that Tcf21-transfected PECs developed 3-4 or sometimes more than 5 centrosomes. By the staining for $\alpha$-tubulin, we identified that Tcf21-transfected cells developed multiple spindle apparatuses which were arrested in the anaphase (Fig. 3D). The percentage of cells with such a multiple and incomplete mitosis was up to $28 \pm 5 \%$ compared to the control ( $2 \pm 3 \%$ ) (Fig. 3E). Moreover, $14 \pm 2 \%$ of the Tcf 21 -transfected PECs showed a significant increase of tetraploidy in the metaphase preparation compared to the control (Fig. 3F, G).

ChIP-Seq analysis identifies genome wide Tcf21-binding sites

Since Tcf21 seems to play a central role for the maintenance of the glomerulus in vivo, we wanted to identify important and novel binding partners of TCF21. Therefore, we performed a chromatin immunoprecipitation followed by DNA-Sequencing (ChIP-Seq) of chromatin isolated from Tcf21-transfected PECs. The data were compared to the control cells that were transfected with an empty vector.

Our ChIP-Seq analysis identified 9125 peaks (putative Tcf21 target genes). To create density distributions around transcription start sites (TSSs), heat maps were created using SeqMINER [37] (Fig. 4A). We next mapped these Tcf21-binding sites and found about 54\% of Tcf21-binding sites within $\pm 5 \mathrm{kbp}$ of any TSS (Fig. 4B). $76 \%$ of these binding sites were approximately $\pm 1 \mathrm{kbp}$ around the TSSs. The availability of sequence information across a large number of TF binding sites allowed the identification of the canonical binding sequence of Tcf21. 

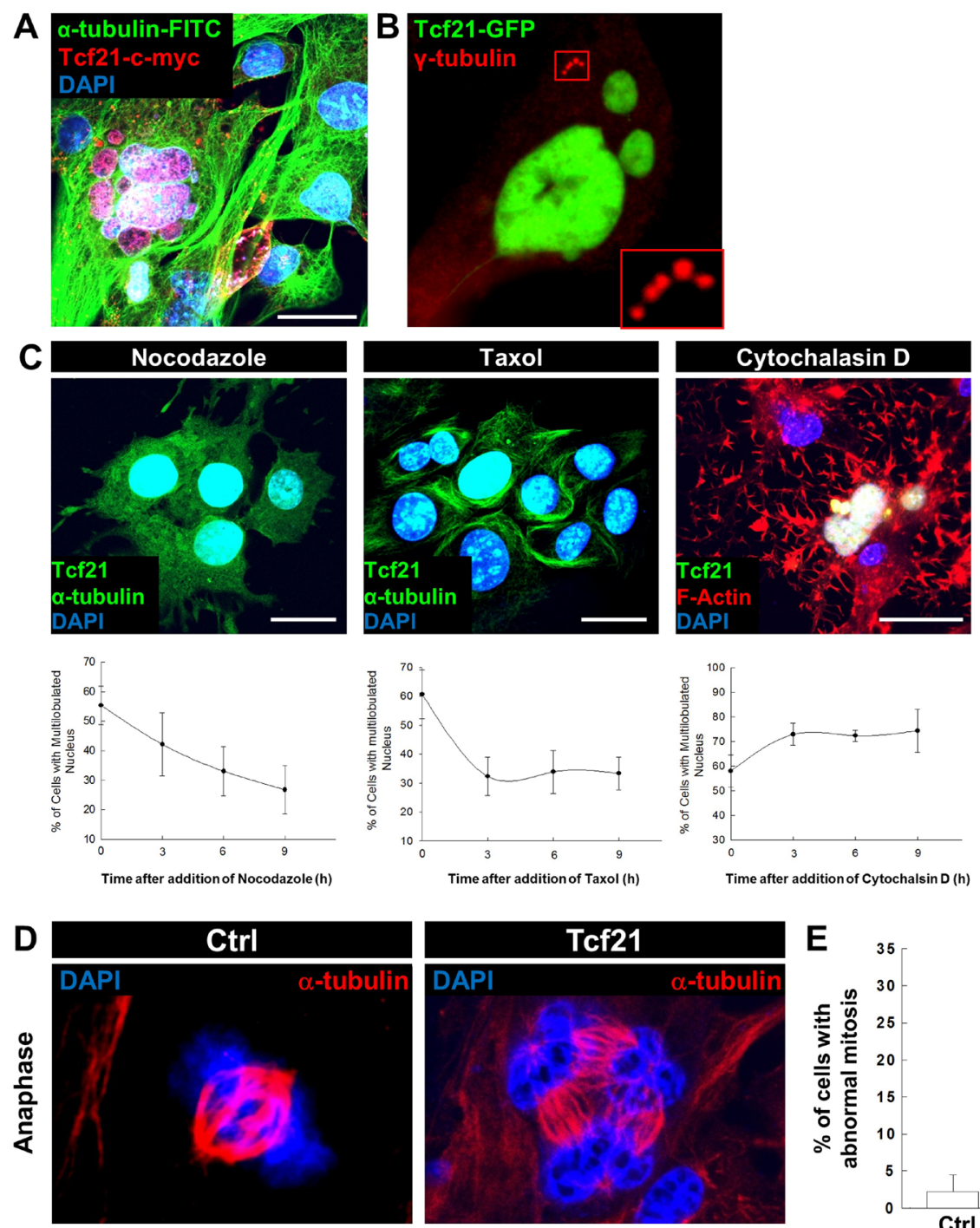

$\mathbf{F}$
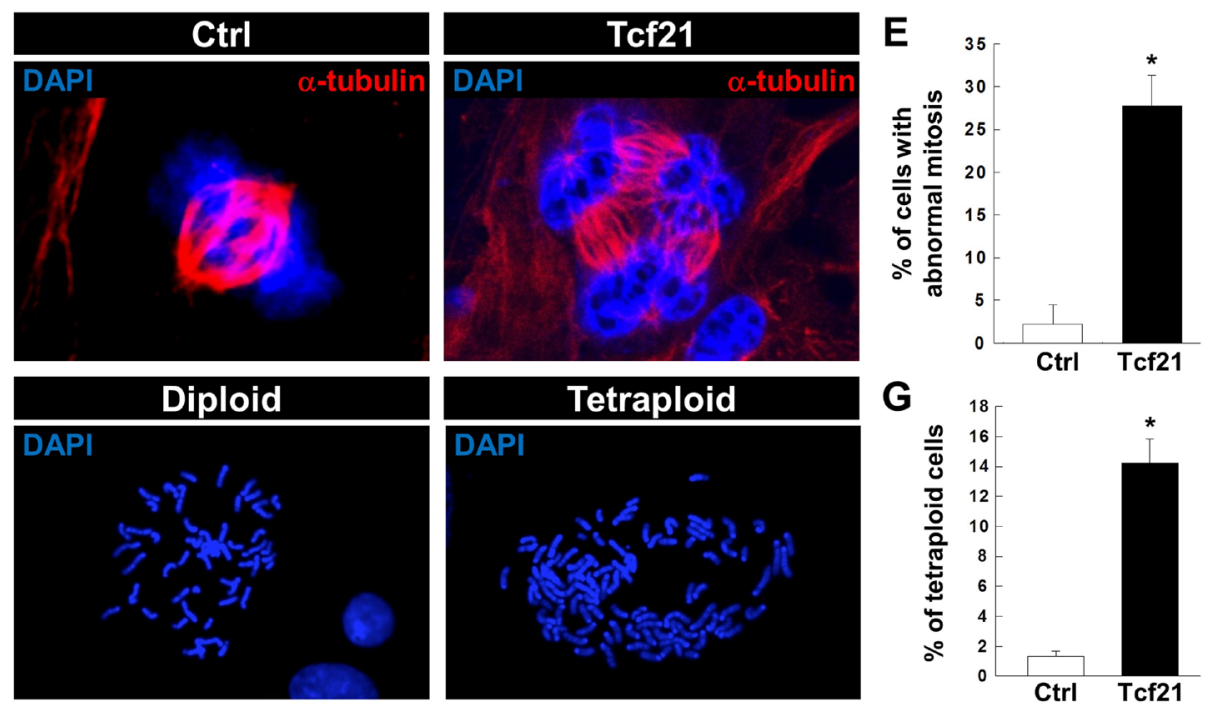

$\mathbf{G}$

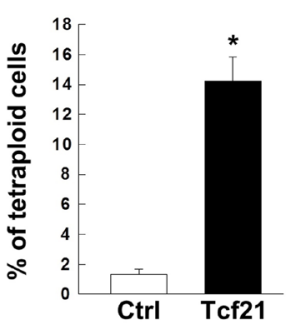

Fig. 3. Tcf 21 induced MBM is accompanied with multiplication of centrosomes and tetraploidy. (A) Tcf21-cmyc transfected PECs were stained with anti- $\alpha$-tubulin-FITC (green), DAPI (DNA, blue) and with antibodies against c-myc (shown in red). Scale bar represents $50 \mu \mathrm{m}$. (B) Immunostaining of $\gamma$-tubulin (red) in PECTcf21 transfected cells (green) revealed multiplication of centrosomes. (C) Immunostaining of Tcf21-tGFP transfected cells after treatment with nocodazole, taxol and cytochalasin D (scale bars represent $25 \mu \mathrm{m}$ ). Percentages of cells with multilobulated nuclei were followed over 9 hours after treatment. (D) Transfection of PECs with Tcf21 increased the number of cells with multiple spindle apparatus, shown by immunofluorescence staining with anti- $\alpha$-tubulin (red) during the anaphase. (E) Percentage of cells with abnormal mitosis. (F) Staining of chromosomes (diploid vs tetraploid) visualized by DAPI staining. (G) Percentage of cells with tetraploidy. Data are presented as means $\pm S D ;{ }^{*} \mathrm{p}<0.05$. 
A

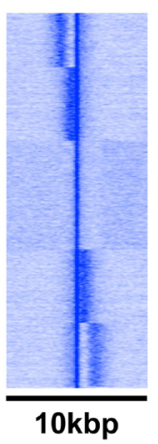

B

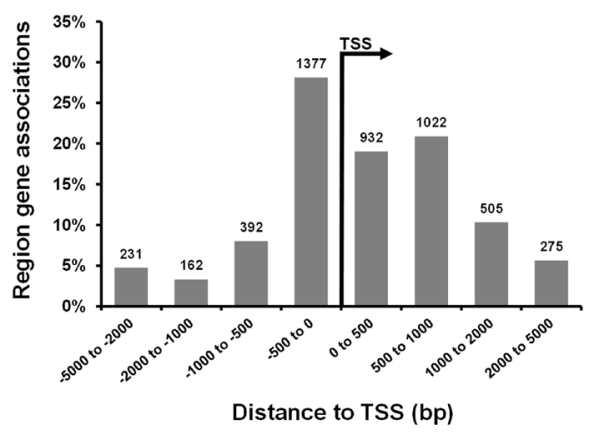

C

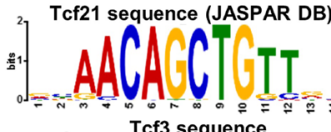
${ }^{2} \quad$ Tcf3 sequence

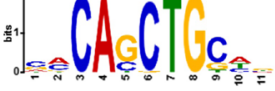

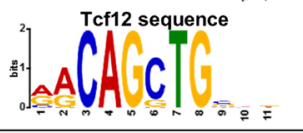

Tcf21 sequence (DREME-ChIP)

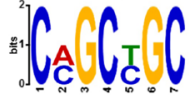

D Cell cycle

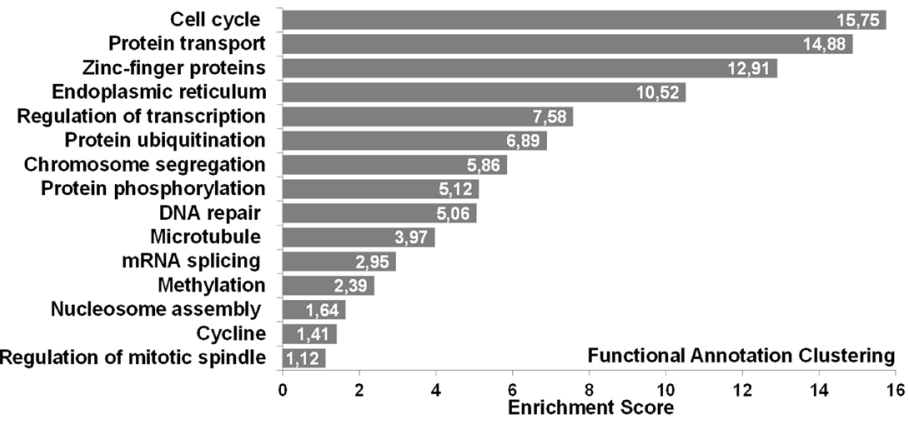

E
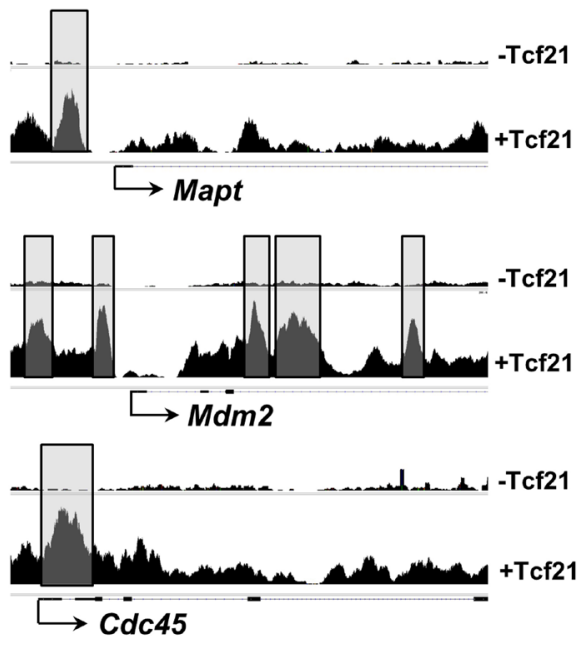

$\mathbf{F}$

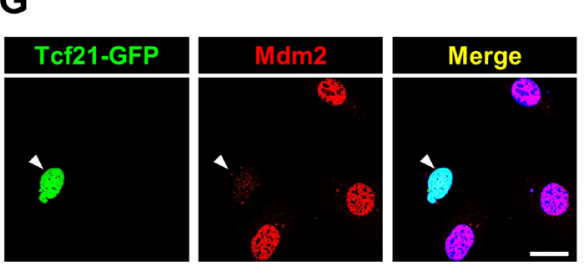

Fig. 4. ChIP-Seq analysis of Tcf 21 targets and binding sites. (A) Density distributions of Tcf 21 peaks around transcription start sites (TSSs) of target genes. (B) Mapping of peaks suggests that Tcf21 is predominately working near the TSS. $54 \%$ of Tcf21-binding sites were within $\pm 5 \mathrm{kbp}$ of any TSS. (C) De novo TF motif enrichment within TCF21 peaks by DREME (Discriminative Regular Expression Motif Elicitation) identified the nucleotide sequence CAGCTG and compared with known motifs from the JASPAR database from Tcf21 and his binding partners Tcf3 and Tcf12. (D) Functional annotation clustering of Tcf21 targets by DAVID. (E) ChIP-Seq analysis identifies direct binding (marked peaks) of Tcf21 close to the loci of Mapt, $M d m 2$ and $C d c 45$. Tracks were generated from three independent Tcf21-ChIP-Seq data sets and visualized by using Integrative Genomics Viewer. (F) qRT-PCR analysis of total mRNA isolated from PEC-Ctrl and PECTcf21. Expression of Mapt increased after transfection with Tcf21. The mRNA level of Mdm2 and Cdc45 decreased. qRT-PCR experiments were normalized to PEC-Ctrl. Actb and Rpl32 served as reference genes $(\mathrm{n} \geq 3$, means \pm SEM). (G) Immunostaining showed a strong down-regulation of Mdm2 (red) expression in PEC-Tcf21 transfected cells (green, marked by arrow) compared to untransfected cells. Scale bar represents $25 \mu \mathrm{m} .{ }^{* * *} \mathrm{p}<0.001,{ }^{* *} \mathrm{p}<0.01$. 


\section{Cellular Physiology Cell Physiol Biochem 2021;55:48-67 \begin{tabular}{ll|l} 
and Biochemistry $10.33594 / 000000378$ & $\begin{array}{l}\text { Published online: } 19 \text { June } 2021 \\
\text { Cell Physiol Biochem Press GmbH\&Co. KG }\end{array}$
\end{tabular}}

By de novo TF motif enrichment within the Tcf21 peaks, we identified the nucleotide sequence CAGCTG (23.6\% of peaks, $P=4.8 \mathrm{e}-042$ ) (Fig 4C). We found that this sequence matched the CANNTG sequence. This is a common E-box binding motif used by bHLH factors. Moreover, this sequence is identical to the E-box motif that is known to mediate the binding of bHLH partners of Tcf21, including Tcf12 and Tcf3 (Fig. 4C) [39].

Interestingly, many of these Tcf 21 target genes are involved in the regulation of the cell cycle, cell division, microtubule-based processes and chromosome segregation (Supplementary Table 4).

Additionally, DAVID was used to perform functional annotation clustering on peaks in relation to TSSs [34]. Peak-associated genes showed also a clear enrichment of cell cycle genes (Fig. 4D). We found several Tcf21 peaks in the promoter regions of cell cycle genes like Mapt, Mdm2 or Cdc45 (peaks highlighted with gray boxes in Fig. 4E). By qRT-PCR, we showed that Mapt was highly up-regulated in the presence of Tcf21 (92 $\pm 12 \%)$ (Fig. 4F). In contrast, Cdc45 which decreased by $52 \pm 8 \%$ as well as $\mathrm{Mdm} 2$ by $55 \pm 10 \%$, a protein know to induce the mitotic catastrophy (Fig. 4F). The downregulation of Mdm2 due to Tcf21 transfection was also confirmed by immunostaining (Fig. 4G). Furthermore, we found Tcf21 bindings sites in the promoter regions of p53 (Trp53; NM_001127233; Tcf21 peak 43bp from TSS) and p21 (Cdkn1a; NM_001111099; Tcf21 peak -38bp from TSS), which are important regulators of the cell cycle.

\section{Tcf21 regulates the expression of specific cyclins}

Since Tcf21 induced incomplete mitosis, we studied the expression of specific cyclins like D1 and D2 after the transfection with Tcf21 (Fig. 5A). By immunofluorescence staining we have found a downregulation of cyclin D1 and an upregulation of cyclin D2.

By qRT-PCR, we demonstrated that cyclin D1 and B1 are significantly reduced by $49 \pm 7 \%$ and $58 \pm 8 \%$, respectively, due to the expression of Tcf21 in PECs. In contrast, the expression of cyclin D2 and E1 was significantly increased by $153 \pm 20 \%$ and $150 \pm 13 \%$ (Fig. 5B).

Fig. 5. Tcf21 influences the expression of various cyclins. (A) Immunofluorescence staining showed a strong downregulation of cyclin D1 (red) and an upregulation of cyclin D2 (red) expression in PEC-Tcf21 transfected cells (green) compared to untransfected cells. Scale bar represents $25 \mu \mathrm{m}$. (B) qRT-PCR analysis of total mRNA isolated from PEC-Ctrl and PECTcf21. Expression of cyclin D1 and B1 is significant reduced after transfection of PECs with Tcf21. In contrast, the expression of cyclin D2 and E1 increased. Actb and Rpl32 served as reference genes $(\mathrm{n} \geq 3$, means \pm SEM).

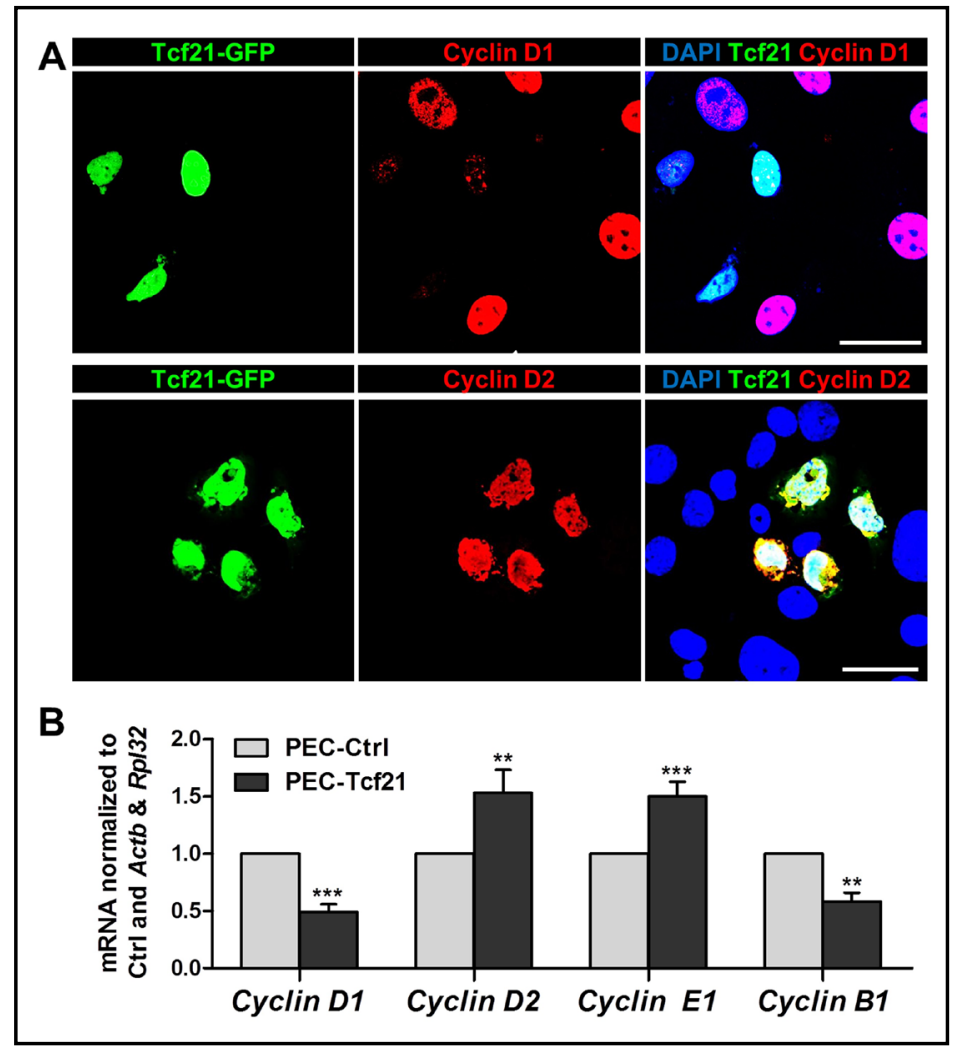




\section{YY1 rescues the Tcf21-induced MBM}

Since it is known that YY1, an important transcriptional repressor protein, is able to regulate de-/differentiation, we studied the expression of YY1 in dependence on Tcf21. We have found by qRT-PCR that YY1 is significantly downregulated $(-52 \pm 7 \%)$ in Tcf21-PECs (Fig. 6B) which was confirmed by immunofluorescence staining (Fig. 4A) and Western blot $(-48 \pm 8 \%)$ (Fig. 6C, D).

Moreover, we found that the co-expression of YY1 in Tcf21-PECs rescued the MBM. We determined a significant reduction of multilobulation, budding as well as tetraploidy (by $62 \%$ ) shown in Fig. 6E and F. These results demonstrated that YY1 and Tcf21 are important regulators of the cell cycle.

\section{TCF21 expression is down-regulated in patients suffering from diabetic nephropathy}

An analysis of microarray data of the Nephroseq database [40-42] has shown that the expression of TCF21 in glomeruli was 3.4 times higher compared to the expression in the tubules of human kidneys (Fig. 7A). However, the expression of Tcf21 mRNA was significantly decreased in mice (2.6 times) and human patients (6.3 times) suffering from diabetic nephropathy (DN) (Fig. 7B).

These results were verified by single mRNA in situ hybridization (Fig. 7C) of human biopsies of patients suffering from DN and FSGS compared to healthy control. The results suggest that podocytes in patients with DN tend to have a lower expression of Tcf21, which could then influence the maintenance of the podocytes. Furthermore, we measured the mRNA expression of TCF21 in microdissected glomeruli originated from renal biopsies of patients suffering from DN and FSGS and compared to mRNA levels of healthy living donors (Fig. 7D) (European Renal cDNA Bank) [25, 26]. We observed that patients with DN showed a significant decrease of TCF21 mRNA compared to the control (log fold change: -0.44). In contrast, patients suffering from focal segmental glomerulosclerosis (FSGS), showed a slight, but significant increase of TCF21 mRNA expression (log fold change: 0.19 ).

\section{Discussion}

Dedifferentiation and loss of podocytes are major causes for the development of severe kidney diseases like FSGS and DN. Since podocytes are growth-restricted, the loss of podocytes cannot be compensated, resulting finally in the development of end-stage renal disease (ESRD). Since several years, there is an ongoing debate whether podocyte progenitor cells exists in or nearby the glomerulus. The groups of Moeller, Romagnani and Shankland have demonstrated that PECs, flat epithelial cells covering the inner side of Bowman's capsule, function as progenitor cells under specific circumstances [4, 6, 11, 43-45]. Therefore, it is of great interest to reveal the mechanisms involved in a possible transformation of PECs into podocyte-like cells as it was described for other cell types like neurons and cardiomyocytes. Parmar and colleagues showed that fibroblasts could directly differentiate into neurons after transfection with three specific transcription factors [46]. Recently, we found that the expression of the transcription factor Dach1 switched PECs into podocyte-like cells which expressed the podocyte specific protein synaptopodin [47].

Several publications have shown that the transcription factor Tcf21 is important for the development of a number of cell types during embryogenesis of the heart, lung, kidney and spleen [17-22]. As a potential candidate for the transdifferentiation of PECs into podocytelike cells, Tcf21 which is weakly expressed in PECs in vivo, was investigated.

Our study revealed that the expression of Tcf21 in PECs resulted in a significant downregulation of the PEC-specific proteins caveolin-1, $\beta$-catenin and Pax2 suggesting that PECs de-differentiation has started. Additionally, we found an upregulation of CD2AP, a podocytes-specific as well as essential slit membrane protein indicating a transition of Tcf21-transfected PECs into podocyte-like cells. 


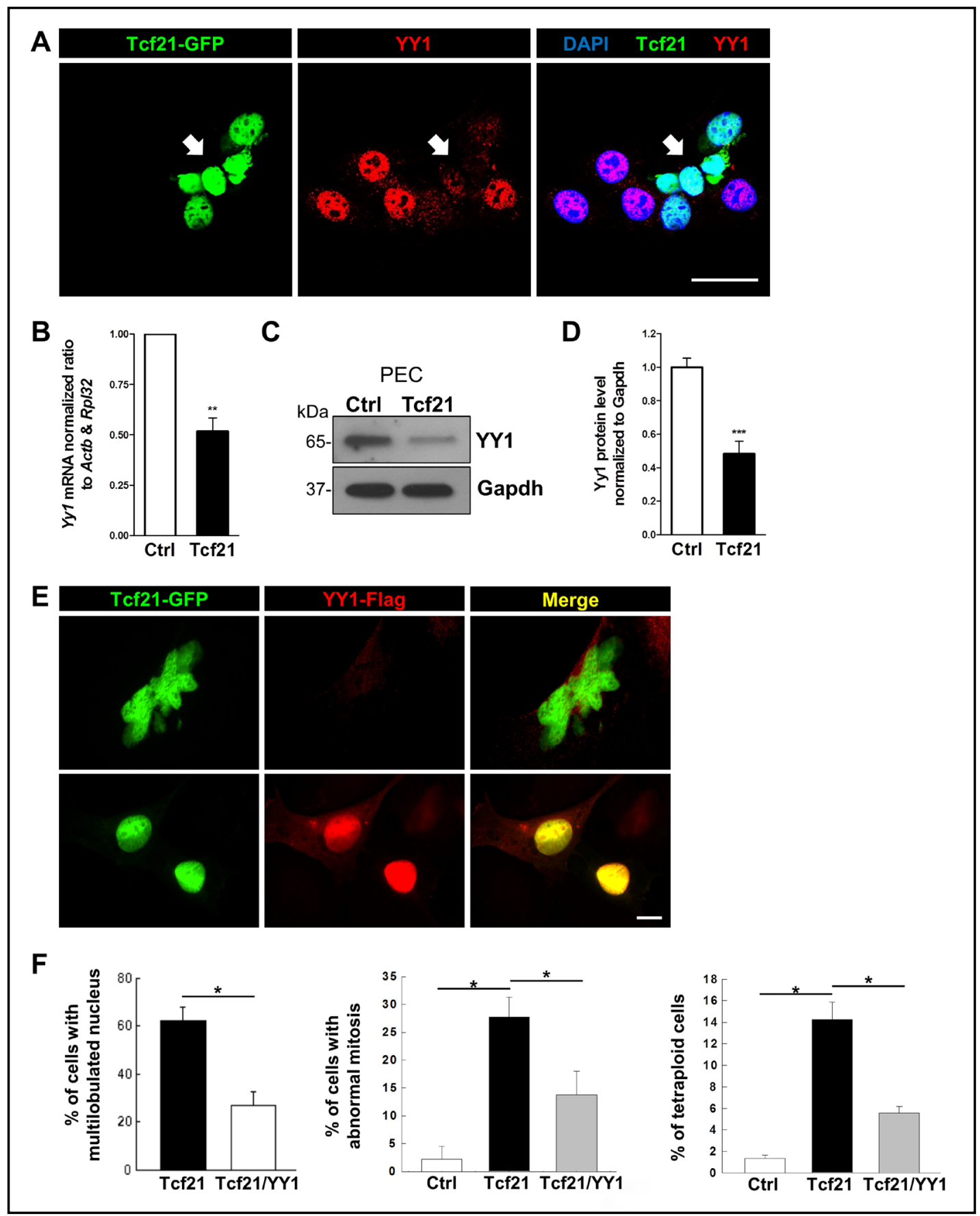

Fig. 6. Tcf21 downregulates the transcription factor YY1, but YY1 coexpression rescues MBM. (A) Immunostaining showed a strong down-regulation of YY1 (red) expression in PEC-Tcf21 transfected cells (green) compared to untransfected cells. Scale bar represents $25 \mu \mathrm{m}$ (B) Yy1 mRNA quantification confirmed IF analysis. Yy1 expression significant reduced in PEC-Tcf21 transfected cells. (C) Western blot analysis showed strong downregulation of YY1. (D) Relative YY1 protein levels on Western blots were quantified for PEC-Ctrl (grey bar) to PEC-Tcf21 transfected cells (white bar) and revealed a significant downregulation of YY1 after transfection with Tcf21 (n=7). (E, F) Co-expression of YY1 (red) and Tcf21 (green) rescues the multilobulation of the nuclei and reduced the number of cells with abnormal mitosis and tetraploidy. Data are presented as means \pm SEM; ${ }^{* * *} \mathrm{p}<0.001,{ }^{* *} \mathrm{p}<0.01,{ }^{*} \mathrm{p}<0.05$. 


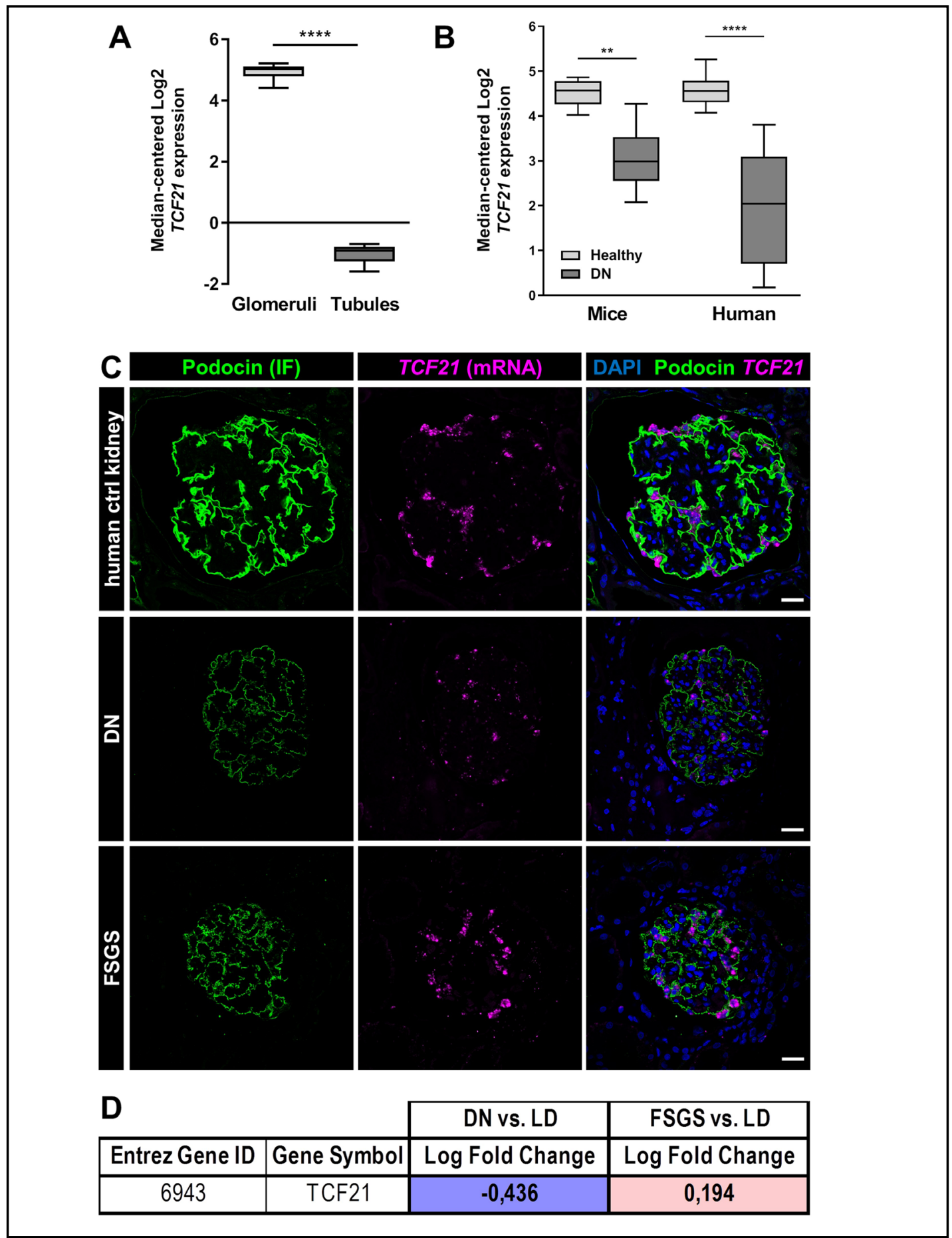

Fig. 7. Diseased glomeruli show altered Tcf21 expression. (A) Median-centered Log2 TCF21 expression in glomeruli (5.0) and tubulointerstitium (-0.9) of human kidney ( $n=6$; p-value: 1,70e-11). (B) The glomerular RNA microarray analysis of non-diabetic $(n=5)$, diabetic mice $(n=7)$, human ctrl $(n=13)$ and human patients suffering from DN ( $\mathrm{n}=9$ ) revealed a significant downregulation of TCF21 mRNA expression. Data were taken from Nephroseq Research Edition (Ann Arbor, University of Michigan; www.nephroseq.org); ${ }^{* * * *} \mathrm{p}<0.0001$, ** $\mathrm{p}<0.01$. (C) In situ hybridization of human kidney of DN (diabetic nephropathy), FSGS (focal segmental glomerulosclerosis) and healthy living donors with a specific TCF21 probe. Nuclei were stained with Hoechst (blue). Immunostaining of podocin is shown in green. Scale bars represent $25 \mu \mathrm{m}$. (D) TCF21 mRNA expression level of microdissected glomeruli from renal biopsies of human patients suffering from DN ( $\mathrm{n}=14)$ and FSGS ( $n=23$ ) compared with healthy living donors (LD; $n=42$ ). Data show logged fold change; q-value $<0.05$. 
To study which genes might be activated by Tcf21, we performed ChIP-Seq analysis of Tcf21-transfected PECs. The analysis revealed that Tcf 21 binds to specific promoter regions of e. g. cell cycle-regulating genes as well as microtubule-associated proteins. Therefore, we studied the expression of cyclin D1 and cyclin D2 which are important for cell cycle and cell division. It has been already shown that cyclin D1, which is essential for the induction of DNA synthesis as well as for cell proliferation [48], controls the proliferation of PECs during development and is constitutively expressed in PECs $[49,50]$. However, since podocytes are postmitotic, cyclin D1 is not expressed in podocytes in vivo [49]. Our data have shown that cyclin D1 is downregulated after the expression of Tcf21 in PECs which seems to reflect the in vivo situation of podocytes. Interestingly, we observed that cyclin D2 which is responsible for the transition of the cell cycle from G1 to S phase, is upregulated after the expression of Tcf21. Whether cyclin D2 could replace cyclin D1 function is not clear.

Beside this, we identified the promoter region of the cell division cycle protein 45 (Cdc45), a protein that is essential for the replication of the DNA, as a binding site for Tcf21 by ChIP-Seq analysis. We found that Cdc45 is downregulated in PECs after the transfection with Tcf21. Since Cdc45 is responsible for proper replication, it makes sense that Cdc45 became downregulated after Tcf 21 transfection.

The promoter region of the microtubule-associated protein Mapt, which is only expressed in podocytes and not in PECs in vivo [51, 52], was also identified as a binding sites for Tcf21. We revealed that the expression of Mapt is significantly upregulated in Tcf21transfected PECs. These data support our hypothesis that Tcf21 induces a transition of PECs into podocyte-like cells.

Interestingly, we observed that the Tcf21 expression in PECs induced multilobulation, budding of the nuclei and the formation of micronuclei (MBM). Further, Tcf21-induced MBM was often accompanied by a multiplication of centrosomes and tetraploidy. In combination with the regulation of cyclins, these data suggest that Tcf21 regulate the cell cycle as well as the mitosis in cultured PECs similar to the findings in adrenocortical and hepatocarcinoma tumor cells [53]. Since we have found that Mdm2, an E3 ubiquitin-protein ligase is responsible for the mitotic catastrophe of podocytes due to an inhibition of the p53-dependent apoptosis pathway [54, 55], we studied whether Tcf21 binds the promoter region of Mdm2. Indeed, we found that Tcf21 binds the promoter region of $\mathrm{Mdm} 2$ as well as down-regulates the expression of Mdm2 determined by qRT-PCR and by immunhistological staining. Since Mdm2 inhibits and degrades p53, a protein essential for cell arrest as well as apoptosis [56-59], one might suggest that MBM might be the results of the Mdm2 inhibition due to the expression of Tcf21. Alternatively; Tcf21 could directly regulate the expression of p53 since we identified a binding site of Tcf 21 to the promoter region of p53.

These results might explain one function of Tcf 21 which is strongly expressed in podocytes in vivo to avoid mitosis because mitosis would change the complex 3-D morphology of differentiated podocytes resulting in a leaky filtration barrier. This hypothesis is supported by the findings that podocyte-specific Tcf 21 knockout mice develop massive proteinuria [23].

Since it was reported that the transcription factor YY1 is an negative regulator of p53 as well as of p21 [60-64], another important protein for cell cycle regulation and that the loss of YY1 resulted in polyploidy and chromatid aberrations [65], we wanted to know whether we could rescue the Tcf21-induced MBM by the co-expression of YY1. Indeed, we observed a complete rescue of the MBM suggesting a role of YY1 in the differentiation of podocytes. That YY1 might play an important role in the transition of undifferentiated into differentiated podocytes was nicely shown by Jha and colleagues [66]. Furthermore, it was shown that the expression of YY1 ameliorates podocyte damage in diabetic nephropathy (DN) [67].

To study the expression of Tcf21 in patients with podocytopathy, we stained biopsies of patients suffering from DN. We have found that not only the protein expression was reduced, but especially the expression of Tcf21 mRNA was significantly downregulated in the biopsies of the patients with DN which was determined by RNAscope ${ }^{\circledR}$ as well as by Nephroseq data analysis. This is in nice accordance with the results found in $\mathrm{db} / \mathrm{db}$ mice where Tcf 21 is significantly downregulated in mice at an age of 7 weeks [68]. Surprisingly, Usui and 
coworkers have shown a very faint expression of Tcf21 in their control kidneys and a massive increase of Tcf 21 expression in biopsies of patients with membranous glomerulonephritis [69]. However, there might be a problem with the control tissue because it is well-known that Tcf21 is strongly expressed in healthy podocytes.

\section{Conclusion}

Taken together, we demonstrated that the transcription factor Tcf21 is an important regulator of essential cell cycle genes, MBM, centrosome replication as well as an inductor of tetraploidy. Furthermore, we could show that Tcf 21 is able to transdifferentiate PECs into podocyte-like cells and became downregulated during the dedifferentiation of podocytes in patients suffering from DN. These results might be helpful to find therapeutic therapies to avoid podocytopathies.

\section{Acknowledgements}

The authors thank Mandy Weise for technical assistance and Robert Weissmann and Lars Jensen for ChIP-Seq bioinformatic analysis. Part of the work was also supported by an Emerging Fields Initiative (EFI) for Cell Cycle in Disease and Regeneration (CYDER) from the Friedrich-Alexander-Universität Erlangen-Nürnberg (FAU) (Germany). We also thank all participating centers of the European Renal cDNA Bank - Kröner-Fresenius biopsy bank (ERCB-KFB) and their patients for their cooperation. Active members at the time of the study please see (Shved et al., Sci Rep 2017;7(1):8576).

\section{Author Contributions}

The study was designed by NE, KE and FK; FK and SS contributed to the cell culture experiments; FK performed ChIP-Seq, supported by AWK; biopsies were handled and analyzed by FK, NA, FS and KA; SS and FS performed RNAscope ${ }^{\circledR}$; all other experiments were performed by FK; experimental data was analyzed by FK; FK, NE and KE wrote the main manuscript text. FK prepared figures. All authors reviewed the manuscript.

\section{Funding}

This work was supported by a grant of the European Foundation for the Study of Diabetes/ Novo Nordisk to KE and by a grant of the EU (COST action BM0702 "Kidney and Urinary Proteomics - EuroKUP") and of the Federal Ministry of Education and Research (BMBF, grant 01GM1518B, STOP-FSGS) to NE as well as by the Südmeyer und Dr. Büchtemann Stiftung. This work was also supported by the Research Network Molecular Medicine of the University Medicine Greifswald. The ERCB-KFB was supported by the Else Kröner-Fresenius Foundation.

\section{Disclosure Statement}

The authors declare no competing financial interests.

\section{References}

1 Berger K, Moeller MJ: Podocytopenia, parietal epithelial cells and glomerulosclerosis. Nephrol Dial Transplant 2014;29:948-950.

2 Marshall CB, Shankland SJ: Cell cycle and glomerular disease: a minireview. Nephron Exp Nephrol 2006;102:e39-48. 


\section{Cellular Physiology Cell Physiol Biochem 2021;55:48-67

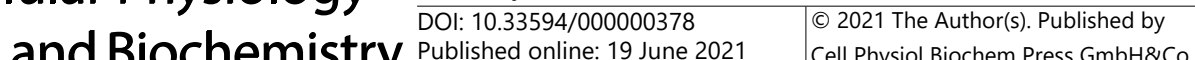 \\ \begin{tabular}{l|l} 
Published online: 19 June 2021 Cell Physiol Biochem Press GmbH\&Co. KG \\
\hline
\end{tabular} \\ Kliewe et al.: The Role of Tcf21 for Transdifferentiation of PECs to Podocytes}

3 Wharram BL, Goyal M, Wiggins JE, Sanden SK, Hussain S, Filipiak WE, Saunders TL, Dysko RC, Kohno K, Holzman LB, Wiggins RC: Podocyte depletion causes glomerulosclerosis: diphtheria toxin-induced podocyte depletion in rats expressing human diphtheria toxin receptor transgene. J Am Soc Nephrol 2005;16:2941-2952.

4 Appel D, Kershaw DB, Smeets B, Yuan G, Fuss A, Frye B, Elger M, Kriz W, Floege J, Moeller MJ: Recruitment of podocytes from glomerular parietal epithelial cells. J Am Soc Nephrol 2009;20:333-343.

5 Berger K, Schulte K, Boor P, Kuppe C, van Kuppevelt, Toin H, Floege J, Smeets B, Moeller MJ: The regenerative potential of parietal epithelial cells in adult mice. J Am Soc Nephrol 2014;25:693-705.

6 Eng DG, Sunseri MW, Kaverina NV, Roeder SS, Pippin JW, Shankland SJ: Glomerular parietal epithelial cells contribute to adult podocyte regeneration in experimental focal segmental glomerulosclerosis. Kidney Int 2015;88:999-1012.

7 Guhr SSO, Sachs M, Wegner A, Becker JU, Meyer TN, Kietzmann L, Schlossarek S, Carrier L, Braig M, Jat PS, Stahl RAK, Meyer-Schwesinger C: The expression of podocyte-specific proteins in parietal epithelial cells is regulated by protein degradation. Kidney Int 2013;84:532-544.

8 Kietzmann L, Guhr SSO, Meyer TN, Ni L, Sachs M, Panzer U, Stahl RAK, Saleem MA, Kerjaschki D, Gebeshuber CA, Meyer-Schwesinger C: MicroRNA-193a Regulates the Transdifferentiation of Human Parietal Epithelial Cells toward a Podocyte Phenotype. J Am Soc Nephrol 2015;26:1389-1401.

9 Kuppe C, Gröne H, Ostendorf T, van Kuppevelt, Toin H, Boor P, Floege J, Smeets B, Moeller MJ: Common histological patterns in glomerular epithelial cells in secondary focal segmental glomerulosclerosis. Kidney Int 2015;88:990-998.

10 Ohse T, Vaughan MR, Kopp JB, Krofft RD, Marshall CB, Chang AM, Hudkins KL, Alpers CE, Pippin JW, Shankland SJ: De novo expression of podocyte proteins in parietal epithelial cells during experimental glomerular disease. Am J Physiol Renal Physiol 2010;298:F702-F711.

11 Ronconi E, Sagrinati C, Angelotti ML, Lazzeri E, Mazzinghi B, Ballerini L, Parente E, Becherucci F, Gacci M, Carini M, Maggi E, Serio M, Vannelli GB, Lasagni L, Romagnani S, Romagnani P: Regeneration of glomerular podocytes by human renal progenitors. J Am Soc Nephrol 2009;20:322-332.

12 Zhang J, Hansen KM, Pippin JW, Chang AM, Taniguchi Y, Krofft RD, Pickering SG, Liu Z, Abrass CK, Shankland SJ: De novo expression of podocyte proteins in parietal epithelial cells in experimental aging nephropathy. Am J Physiol Renal Physiol 2012;302:F571-F580.

13 Kreidberg JA, Sariola H, Loring JM, Maeda M, Pelletier J, Housman D, Jaenisch R: WT-1 is required for early kidney development. Cell 1993;74:679-691.

14 Miner JH, Morello R, Andrews KL, Li C, Antignac C, Shaw AS, Lee B: Transcriptional induction of slit diaphragm genes by Lmx1b is required in podocyte differentiation. J Clin Invest 2002;109:1065-1072.

15 Sadl V, Jin F, Yu J, Cui S, Holmyard D, Quaggin S, Barsh G, Cordes S: The mouse Kreisler (Krml1/MafB) segmentation gene is required for differentiation of glomerular visceral epithelial cells. Dev Biol 2002;249:16-29.

16 Takemoto M, He L, Norlin J, Patrakka J, Xiao Z, Petrova T, Bondjers C, Asp J, Wallgard E, Sun Y, Samuelsson T, Mostad P, Lundin S, Miura N, Sado Y, Alitalo K, Quaggin SE, Tryggvason K, Betsholtz C: Large-scale identification of genes implicated in kidney glomerulus development and function. EMBO J 2006;25:11601174.

17 Quaggin SE, Vanden Heuvel, G B, Igarashi P: Pod-1, a mesoderm-specific basic-helix-loop-helix protein expressed in mesenchymal and glomerular epithelial cells in the developing kidney. Mech Dev 1998;71:3748.

18 Quaggin SE, Schwartz L, Cui S, Igarashi P, Deimling J, Post M, Rossant J: The basic-helix-loop-helix protein pod1 is critically important for kidney and lung organogenesis. Development 1999;126:5771-5783.

19 Acharya A, Baek ST, Huang G, Eskiocak B, Goetsch S, Sung CY, Banfi S, Sauer MF, Olsen GS, Duffield JS, Olson EN, Tallquist MD: The bHLH transcription factor Tcf 21 is required for lineage-specific EMT of cardiac fibroblast progenitors. Development 2012;139:2139-2149.

20 Hidai H, Bardales R, Goodwin R, Quertermous T, Quertermous EE: Cloning of capsulin, a basic helixloop-helix factor expressed in progenitor cells of the pericardium and the coronary arteries. Mech Dev 1998;73:33-43.

21 Lu J, Richardson JA, Olson EN: Capsulin: a novel bHLH transcription factor expressed in epicardial progenitors and mesenchyme of visceral organs. Mech Dev 1998;73:23-32. 


\section{Cellular Physiology Cell Physiol Biochem 2021;55:48-67 \begin{tabular}{c|c|c|c|c|} 
DOl: 10.33594/000000378 & 02021 The Author(s). Published by \\
and Biochemistry
\end{tabular} \\ \begin{tabular}{l|ll} 
Published online: 19 June 2021 & Cell Physiol Biochem Press GmbH\&Co. KG \\
\hline
\end{tabular} \\ Kliewe et al.: The Role of Tcf21 for Transdifferentiation of PECs to Podocytes}

22 Lu J, Chang P, Richardson JA, Gan L, Weiler H, Olson EN: The basic helix-loop-helix transcription factor capsulin controls spleen organogenesis. Proc Natl Acad Sci U S A 2000;97:9525-9530.

23 Maezawa Y, Onay T, Scott RP, Keir LS, Dimke H, Li C, Eremina V, Maezawa Y, Jeansson M, Shan J, Binnie M, Lewin M, Ghosh A, Miner JH, Vainio SJ, Quaggin SE: Loss of the podocyte-expressed transcription factor Tcf21/Pod1 results in podocyte differentiation defects and FSGS. J Am Soc Nephrol 2014;25:2459-2470.

24 Kabgani N, Grigoleit T, Schulte K, Sechi A, Sauer-Lehnen S, Tag C, Boor P, Kuppe C, Warsow G, Schordan S, Mostertz J, Chilukoti RK, Homuth G, Endlich N, Tacke F, Weiskirchen R, Fuellen G, Endlich K, Floege J, Smeets $B$, et al.: Primary cultures of glomerular parietal epithelial cells or podocytes with proven origin. PloS One 2012;7:e34907.

25 Cohen CD, Frach K, Schlöndorff D, Kretzler M: Quantitative gene expression analysis in renal biopsies: a novel protocol for a high-throughput multicenter application. Kidney Int 2002;61:133-140.

26 Martini S, Nair V, Keller BJ, Eichinger F, Hawkins JJ, Randolph A, Böger CA, Gadegbeku CA, Fox CS, Cohen CD, Kretzler M: Integrative biology identifies shared transcriptional networks in CKD. J Am Soc Nephrol 2014;25:2559-2572.

27 Cohen CD, Klingenhoff A, Boucherot A, Nitsche A, Henger A, Brunner B, Schmid H, Merkle M, Saleem MA, Koller K, Werner T, Gröne H, Nelson PJ, Kretzler M: Comparative promoter analysis allows de novo identification of specialized cell junction-associated proteins. Proc Natl Acad Sci U S A 2006;103:56825687.

28 Tusher VG, Tibshirani R, Chu G: Significance analysis of microarrays applied to the ionizing radiation response. Proc Natl Acad Sci U S A 2001;98:5116-5121.

29 Pfaffl MW: A new mathematical model for relative quantification in real-time RT-PCR. Nucleic Acids Res 2001;29:e45.

30 Bouter Y, Kacprowski T, Weissmann R, Dietrich K, Borgers H, Brauß A, Sperling C, Wirths O, Albrecht M, Jensen LR, Kuss AW, Bayer TA: Deciphering the Molecular Profile of Plaques, Memory Decline and Neuron Loss in Two Mouse Models for Alzheimer's Disease by Deep Sequencing. Front Aging Neurosci 2014;6:383.

31 Bailey TL, Boden M, Buske FA, Frith M, Grant CE, Clementi L, Ren J, Li WW, Noble WS: MEME SUITE: tools for motif discovery and searching. Nucleic Acids Res 2009;37:W202-W208.

32 Bailey TL: DREME: motif discovery in transcription factor ChIP-seq data. Bioinformatics 2011;27:16531659.

33 Mathelier A, Zhao X, Zhang AW, Parcy F, Worsley-Hunt R, Arenillas DJ, Buchman S, Chen C, Chou A, Ienasescu H, Lim J, Shyr C, Tan G, Zhou M, Lenhard B, Sandelin A, Wasserman WW: JASPAR 2014: an extensively expanded and updated open-access database of transcription factor binding profiles. Nucleic Acids Res 2014;42:D142-D147.

34 Huang DW, Sherman BT, Lempicki RA: Systematic and integrative analysis of large gene lists using DAVID bioinformatics resources. Nat Proc 2009;4:44-57.

35 Chen J, Bardes EE, Aronow BJ, Jegga AG: ToppGene Suite for gene list enrichment analysis and candidate gene prioritization. Nucleic Acids Res 2009;37:W305-W311.

36 Robinson JT, Thorvaldsdóttir H, Winckler W, Guttman M, Lander ES, Getz G, Mesirov JP: Integrative genomics viewer. Nat Biotechnol 2011;29:24-26.

37 Ye T, Krebs AR, Choukrallah M, Keime C, Plewniak F, Davidson I, Tora L: seqMINER: an integrated ChIP-seq data interpretation platform. Nucleic Acids Res 2011;39:e35.

38 Kindt F, Hammer E, Kemnitz S, Blumenthal A, Klemm P, Schlüter R, Quaggin SE, van den Brandt, Jens, Fuellen G, Völker U, Endlich K, Endlich N: A novel assay to assess the effect of pharmaceutical compounds on the differentiation of podocytes. Br J Pharmacol 2017;174:163-176.

39 Murre C, McCaw PS, Baltimore D: A new DNA binding and dimerization motif in immunoglobulin enhancer binding, daughterless, MyoD, and myc proteins. Cell 1989;56:777-783.

40 Lindenmeyer MT, Eichinger F, Sen K, Anders H, Edenhofer I, Mattinzoli D, Kretzler M, Rastaldi MP, Cohen CD: Systematic analysis of a novel human renal glomerulus-enriched gene expression dataset. PloS One 2010;5:e11545.

41 Woroniecka KI, Park, Ae Seo Deok, Mohtat D, Thomas DB, Pullman JM, Susztak K: Transcriptome analysis of human diabetic kidney disease. Diabetes 2011;60:2354-2369.

42 Hodgin JB, Nair V, Zhang H, Randolph A, Harris RC, Nelson RG, Weil EJ, Cavalcoli JD, Patel JM, Brosius FC, Kretzler M: Identification of cross-species shared transcriptional networks of diabetic nephropathy in human and mouse glomeruli. Diabetes 2013;62:299-308. 
43 Kaverina NV, Eng DG, Schneider, Remington R. S., Pippin JW, Shankland SJ: Partial podocyte replenishment in experimental FSGS derives from nonpodocyte sources. Am J Physiol Renal Physiol 2016;310:F1397.

44 Kaverina NV, Eng DG, Freedman BS, Kutz JN, Chozinski TJ, Vaughan JC, Miner JH, Pippin JW, Shankland SJ: Dual lineage tracing shows that glomerular parietal epithelial cells can transdifferentiate toward the adult podocyte fate. Kidney Int 2019;96:597-611.

45 Kaverina NV, Eng DG, Miner JH, Pippin JW, Shankland SJ: Parietal epithelial cell differentiation to a podocyte fate in the aged mouse kidney. Aging 2020;12:17601-17624.

46 Pfisterer U, Kirkeby A, Torper O, Wood J, Nelander J, Dufour A, Björklund A, Lindvall O, Jakobsson J, Parmar M: Direct conversion of human fibroblasts to dopaminergic neurons. Proc Natl Acad Sci U S A 2011;108:10343-10348.

47 Endlich N, Kliewe F, Kindt F, Schmidt K, Kotb AM, Artelt N, Lindenmeyer MT, Cohen CD, Döring F, Kuss AW, Amann K, Moeller MJ, Kabgani N, Blumenthal A, Endlich K: The transcription factor Dach1 is essential for podocyte function. J Cell Mol Med 2018;22:2656-2669.

48 Yang K, Hitomi M, Stacey DW: Variations in cyclin D1 levels through the cell cycle determine the proliferative fate of a cell. Cell Div 2006;1:32.

49 Burnworth B, Pippin J, Karna P, Akakura S, Krofft R, Zhang G, Hudkins K, Alpers CE, Smith K, Shankland SJ, Gelman IH, Nelson PJ: SSeCKS sequesters cyclin D1 in glomerular parietal epithelial cells and influences proliferative injury in the glomerulus. Lab Invest 2012;92:499-510.

50 Shankland SJ, Anders H, Romagnani P: Glomerular parietal epithelial cells in kidney physiology, pathology, and repair. Curr Opin Nephrol Hypertens 2013;22:302-309.

51 Gödel M, Temerinac D, Grahammer F, Hartleben B, Kretz O, Riederer BM, Propst F, Kohl S, Huber TB: Microtubule Associated Protein 1b (MAP1B) Is a Marker of the Microtubular Cytoskeleton in Podocytes but Is Not Essential for the Function of the Kidney Filtration Barrier in Mice. PloS One 2015;10:e0140116.

52 Kobayashi N: Mechanism of the process formation; podocytes vs. neurons. Microsc Res Tech 2002;57:217223.

53 França MM, Ferraz-de-Souza B, Lerario AM, Fragoso, Maria Candida Barisson Villares, Lotfi, Claudimara Ferini Pacicco: POD-1/TCF21 Reduces SHP Expression, Affecting LRH-1 Regulation and Cell Cycle Balance in Adrenocortical and Hepatocarcinoma Tumor Cells. BioMed Res Int 2015;2015:841784.

54 Mulay SR, Thomasova D, Ryu M, Kulkarni OP, Migliorini A, Bruns H, Gröbmayr R, Lazzeri E, Lasagni L, Liapis H, Romagnani P, Anders H: Podocyte loss involves MDM2-driven mitotic catastrophe. J Pathol 2013;230:322-335.

55 Thomasova D, Bruns HA, Kretschmer V, Ebrahim M, Romoli S, Liapis H, Kotb AM, Endlich N, Anders H: Murine Double Minute-2 Prevents p53-Overactivation-Related Cell Death (Podoptosis) of Podocytes. J Am Soc Nephrol 2015;26:1513-1523.

56 Fridman JS, Lowe SW: Control of apoptosis by p53. Oncogene 2003;22:9030-9040.

57 Lane D, Levine A: p53 Research: The Past Thirty Years and the Next Thirty Years. Cold Spring Harb Perspect Biol 2010;2:a000893.

58 Chen J: The Cell-Cycle Arrest and Apoptotic Functions of p53 in Tumor Initiation and Progression. Cold Spring Harb Perspect Med 2016;6:a026104.

59 Aubrey BJ, Kelly GL, Janic A, Herold MJ, Strasser A: How does p53 induce apoptosis and how does this relate to p53-mediated tumour suppression? Cell Death Differ 2018;25:104-113.

60 Sui G, El Bachir Affar, Shi Y, Brignone C, Wall NR, Yin P, Donohoe M, Luke MP, Calvo D, Grossman SR, Shi Y: Yin Yang 1 Is a Negative Regulator of p53. Cell 2004;117:859-872.

61 Gronroos E, Terentiev AA, Punga T, Ericsson J: YY1 inhibits the activation of the p53 tumor suppressor in response to genotoxic stress. Proc Natl Acad Sci U S A 2004;101:12165-12170.

62 Santiago FS, Ishii H, Shafi S, Khurana R, Kanellakis P, Bhindi R, Ramirez MJ, Bobik A, Martin JF, Chesterman CN, Zachary IC, Khachigian LM: Yin Yang-1 Inhibits Vascular Smooth Muscle Cell Growth and Intimal Thickening by Repressing p21 WAF1/Cip1 Transcription and p21 WAF1/Cip1 -Cdk4-Cyclin D1 Assembly. Circ Res 2007;101:146-155.

63 Liu D, Zhang J, Wu Y, Shi G, Yuan H, Lu Z, Zhu Q, Wu P, Lu C, Guo F, Chen J, Jiang K, Miao Y: YY1 suppresses proliferation and migration of pancreatic ductal adenocarcinoma by regulating the CDKN3/MdM2/P53/ P21 signaling pathway. Int J Cancer 2018;142:1392-1404.

64 Sui Y, Wu T, Li F, Wang F, Cai Y, Jin J: YY1/BCCIP Coordinately Regulates P53-Responsive Element (p53RE)Mediated Transactivation of p21Waf1/Cip1. Int J Mol Sci 2019;20:2095. 


\section{Cellular Physiology Cell Physiol Biochem 2021;55:48-67}

\begin{tabular}{ll|l} 
and Biochemistry & $\begin{array}{l}\text { DOl: 10.33594/000000378 } \\
\text { Published online: } 19 \text { June 2021 }\end{array}$ & $\begin{array}{l}\text { O 2021 The Author(s). Published by } \\
\text { Cell Physiol Biochem Press GmbH\&Co. KG }\end{array}$ \\
\cline { 2 - 3 }
\end{tabular}

Kliewe et al.: The Role of Tcf21 for Transdifferentiation of PECs to Podocytes

65 Wu S, Shi Y, Mulligan P, Gay F, Landry J, Liu H, Lu J, Qi HH, Wang W, Nickoloff JA, Wu C, Shi Y: A YY1-IN080 complex regulates genomic stability through homologous recombination-based repair. Nat Struct Mol Biol 2007;14:1165-1172.

66 Jha A, Saha S, Ayasolla K, Vashistha H, Malhotra A, Skorecki K, Singhal PC: MiR193a Modulation and Podocyte Phenotype. Cells 2020;9:1004.

67 Gao P, Li L, Yang L, Gui D, Zhang J, Han J, Wang J, Wang N, Lu J, Chen S, Hou L, Sun H, Xie L, Zou J, Peng C, Lu Y, Peng X, Wang C, Miao J, Ozcan U, et al.: Yin Yang 1 protein ameliorates diabetic nephropathy pathology through transcriptional repression of TGFß1. Sci Transl Med 2019:11:eaaw2050.

68 Makino H, Miyamoto Y, Sawai K, Mori K, Mukoyama M, Nakao K, Yoshimasa Y, Suga S: Altered gene expression related to glomerulogenesis and podocyte structure in early diabetic nephropathy of $\mathrm{db} / \mathrm{db}$ mice and its restoration by pioglitazone. Diabetes 2006;55:2747-2756.

69 Usui J, Yaguchi M, Yamazaki S, Takahashi-Kobayashi M, Kawamura T, Kaneko S, Seshan SV, Ronco P, Yamagata K: Transcription factor 21 expression in injured podocytes of glomerular diseases. Sci Rep 2020;10:11516. 